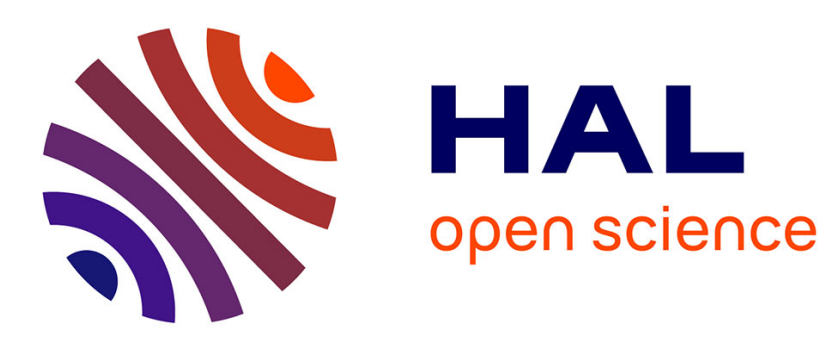

\title{
Time-dependent changes of the electrical conductivity of basaltic melts with redox state
}

\author{
Anne Pommier, Fabrice Gaillard, Michel Pichavant
}

\section{To cite this version:}

Anne Pommier, Fabrice Gaillard, Michel Pichavant. Time-dependent changes of the electrical conductivity of basaltic melts with redox state. Geochimica et Cosmochimica Acta, 2010, 74 (5), pp.16531671. 10.1016/j.gca.2009.12.005 . insu-00442614

\section{HAL Id: insu-00442614 https://hal-insu.archives-ouvertes.fr/insu-00442614}

Submitted on 22 Dec 2009

HAL is a multi-disciplinary open access archive for the deposit and dissemination of scientific research documents, whether they are published or not. The documents may come from teaching and research institutions in France or abroad, or from public or private research centers.
L'archive ouverte pluridisciplinaire HAL, est destinée au dépôt et à la diffusion de documents scientifiques de niveau recherche, publiés ou non, émanant des établissements d'enseignement et de recherche français ou étrangers, des laboratoires publics ou privés. 


\section{TIME-DEPENDENT CHANGES OF THE ELECTRICAL CONDUCTIVITY OF BASALTIC MELTS WITH REDOX STATE}

POMMIER A. ${ }^{1}$, GAILLARD F. ${ }^{1}$ AND PICHAVANT M. ${ }^{1}$

${ }^{1}$ CNRS/INSU, Université d'Orléans, Université François Rabelais-Tours, Institut des Sciences de la Terre d'Orléans (ISTO), UMR 6113, Campus Géosciences, 1A rue de la Férollerie, 45071 Orléans cedex 2, France 


\section{Abstract 300 better)}

The electrical conductivity of basaltic melts has been measured in real-time after $\mathrm{fO}_{2}$ stepchanges in order to investigate redox kinetics. Experimental investigations were performed at 1 atm in a vertical furnace between $1200^{\circ} \mathrm{C}$ and $1400^{\circ} \mathrm{C}$ using air, pure $\mathrm{CO}_{2}$ or $\mathrm{CO} / \mathrm{CO}_{2}$ gas mixtures to buffer oxygen fugacity in the range $10^{-8}$ to 0.2 bars. Ferric/ferrous ratios were determined by wet chemical titrations. A small but detectable effect of $\mathrm{fO}_{2}$ on the electrical conductivity is observed. The more reduced the melt, the higher the conductivity. A modified Arrhenian equation accounts for both $\mathrm{T}$ and $\mathrm{fO}_{2}$ effects on the electrical conductivity. We show that time-dependent changes in electrical conductivity following $\mathrm{fO}_{2}$ step-changes monitor the rate of $\mathrm{Fe}^{2+} / \mathrm{Fe}^{3+}$ changes. The conductivity change with time corresponds to a diffusion-limited process in the case of reduction in $\mathrm{CO}-\mathrm{CO}_{2}$ gas mixtures and oxidation in air. However, a reaction at the gas-melt interface probably rate limits oxidation of the melt under pure $\mathrm{CO}_{2}$. Reduction and oxidation rates are similar and both increase with temperature. Those rates range from $10^{-9}$ to $10^{-8} \mathrm{~m}^{2} / \mathrm{s}$ for the temperature interval $1200-1400^{\circ} \mathrm{C}$ and show activation energy of about $200 \mathrm{~kJ} / \mathrm{mol}$. The redox mechanism that best explains our results involves a cooperative motion of cations and oxygen, allowing such fast oxidation-reduction rates.

\section{INTRODUCTION}

Several studies have revealed the important controls of redox potential, usually quantified as oxygen fugacity $\left(\mathrm{fO}_{2}\right)$, on metal/silicate melt, crystal/melt and gas/melt equilibria (Carmichael and Ghiorso, 1990; Righter and Drake, 1996; Moretti and Papale, 2004; Gaillard and Scaillet, 2009). This makes redox condition of basaltic melts one of the most critical parameter influencing many planetary processes, involving core formation, mantle melting and metasomatism, crystallization of magmas and magma degassing (Righter and Drake, 1996; Herd, 2008; Frost and McCammon, 2008). Several multivalent elements determine the $\mathrm{fO}_{2}$ of basaltic melts $(\mathrm{Fe}, \mathrm{C}, \mathrm{H}, \mathrm{O}, \mathrm{S})$, but the ferric/ferrous ratio of the melt is commonly used to monitor redox changes in magmatic processes (Kress and Carmichael, 1991; Behrens and Gaillard, 2006). The oxygen fugacity of a basalt is generally defined relatively to the one of a solid buffer, such as, from the more reducing to the more oxidizing, Iron-Wustite (IW), Quartz-Fayalite-Magnetite (QFM), Nickel-Nickel Oxide (NNO) (Herd, 2008). 
Present-day basaltic lavas on Earth display a range in oxygen fugacity from 3 log-units below NNO to 4 log-units above NNO, corresponding to ferric/total iron ratios ranging from less than 10 to $~ 70 \%$ (Botcharnikov et al., 2005; Carmichael, 1991). Martian basalts record more reduced oxygen fugacities, ranging from 0.5 log-units to 3.5 log-units below NNO (Herd et al., 2002). Such variations in planetary basalts oxygen fugacity might reflect fundamental heterogeneities in the redox state of their source region but $\mathrm{fO}_{2}$ can be also modified during melting, crystallization and degassing processes. Since such modifications can be kinetically controlled, a correct interpretation of $\mathrm{fO}_{2}$ variabilities requires the understanding of the mechanisms and rate of changes in the redox potential in basalts. In this paper, we use electrical conductivity measurements to further document mechanisms and kinetics of redox changes in basaltic melts.

\section{PREVIOUS WORKS}

Mechanisms of oxidation/reduction of silicate melts have been actively investigated (e.g. Schreiber et al., 1986 and references therein). In H-bearing and $\mathrm{H}$-free basaltic systems, reduction/oxidation reactions are commonly associated with the development of redox reaction fronts and are diffusion-limited (Wendlandt, 1991; Cooper et al., 1996a, b; Everman and Cooper, 2003; Gaillard et al., 2003a). For H-bearing systems, Gaillard et al. (2003b) calculated that $\mathrm{H}_{2}$ mobility should rate-limit redox changes in basalts. In H-free systems, different rate-limiting species have been proposed. Oxidation-reduction reactions have been initially associated to the diffusion of oxygen (self-diffusion of oxygen; Wendlandt, 1991). However, self-diffusion experiments do not involve gain or loss of oxygen $\left({ }^{16} \mathrm{O}-{ }^{18} \mathrm{O}\right.$ substitutions are involved) whereas redox experiments implicitly require a change in the oxygen/cations ratio. Variable-valence ions have been found to enhance oxygen fluxes (Beerkens and de Waal, 1990). Redox experiments are usually related to oxygen $\left(\mathrm{O}_{2}\right)$ chemical diffusion experiments (Schreiber et al., 1986). For glasses or melts of similar composition, oxygen tracer diffusivity $\left(D^{*}\right)$ is commonly several orders of magnitude slower than oxygen chemical diffusivity (D, Schreiber et al., 1986; Cook et al., 1990; Wendlandt, 1991) (Appendix 1). Such discrepancies between O diffusion coefficients have been interpreted in terms of different transport mechanisms, oxygen self- or tracer diffusion involving mobility of discrete cation-oxygen species within the melt while oxygen chemical diffusion is dominated by the migration of cationic species. Cooper et al. (1996b) have demonstrated that the diffusion of an oxygen species is not required during redox reactions in 
melts and that the change in the oxygen/cations ratio is best accommodated by cations rather than oxygen diffusivity due to their greater mobility.

Oxygen self and chemical diffusion studies performed on synthetic (Sasabe and Goto, 1974; Dunn, 1982; Schreiber et al., 1986; Cook et al., 1990; Cook and Cooper, 2000; Reid et al., 2001) and natural silicate melts (Dunn, 1983; Canil and Muehlenbachs, 1990; Wendlandt, 1991; Cooper et al., 1996a) have demonstrated the dependence of both kind of diffusion mechanisms on the melt structure. This was also confirmed by other studies of iron redox reactions (e.g. Magnien et al., 2008). All that tends to underline that the Network Formers ( $\mathrm{Si}, \mathrm{Al}$ ) lower the oxygen diffusivity (D) whereas the Network Modifiers (divalent cations and alkali) have the opposite effect. In basaltic melts, oxygen self-diffusion data were found to be comparable to divalent cations diffusivities. For example, in a basaltic melt at $1300^{\circ} \mathrm{C}$, Muehlenbachs and Kushiro (1974) and Lesher et al. (1996) measured oxygen diffusivities (D*) of $\sim 4.10^{-12} \mathrm{~m}^{2} / \mathrm{s}$ and $6.10^{-12} \mathrm{~m}^{2} / \mathrm{s}$, respectively. This result questions the assumption of Cooper et al. $(1996 \mathrm{a}, \mathrm{b})$ that $\mathrm{c}_{\mathrm{O} 2-} \mathrm{D}_{\mathrm{O} 2-}\left(\right.$ and $\left.\mathrm{c}_{\mathrm{O} 2} \mathrm{D}_{\mathrm{O} 2}\right)<\mathrm{c}_{\text {modifier cations }} \mathrm{D}_{\text {modifier cations, }}, \mathrm{c}_{\mathrm{x}}$ being the concentration of $\mathrm{x}$.

The electrical conductivity, $\sigma$, reveals the mobility of the charge carriers in presence of a gradient in electrical potential and is an efficient probe of mass transfer processes within silicate melts and magmas. Previous studies have shown that it is extremely sensitive to many parameters, including temperature $(\mathrm{T})$, pressure $(\mathrm{P})$, melt composition (Tyburczy and Waff, 1983, 1985; Gaillard, 2004; Gaillard and Iacono Marziano, 2005; Pommier et al., 2008). However, the dependence of electrical conductivity of silicate melts to redox conditions has remained poorly documented. The only study on the subject (Waff and Weill, 1975) found no significant variation in $\sigma$ with $\mathrm{fO}_{2}$ and suggested to neglect the influence of $\mathrm{fO}_{2}$ on the electrical properties of silicate melts.

We have undertaken a systematic investigation of the influence of $\mathrm{fO}_{2}$ on the electrical response of two different basaltic melts at $0.1 \mathrm{MPa}$ and different temperatures. The study was motivated by (1) the need to reexamine the conclusions of Waff and Weill (1975) in the light of recent methodological advances in the field of electrical measurements and (2) the need to understand redox kinetics and mechanisms in natural silicate melts, the electrical conductivity being here used as a probe for investigating mass transfer properties. Modern techniques of measurements of electrical conductivity such as impedance spectroscopy (Huebner and Dillenburg, 1995) allows the electrical response to be separated in terms of an imaginary and a real part, the latter corresponding unambiguously to the electrical resistance of the sample. In the case of oxidation/reduction reactions, the real time electrical response of the melts was not monitored in previous studies (Waff and Weill, 1975) and is therefore unknown. In our study, the 
electrical conductivity was continuously measured from step changes in $\mathrm{fO}_{2}$ until the attainment of redox equilibrium. In turn, this allows conductivity changes to be interpreted in terms of kinetics and mechanisms of redox changes in the melt. Equilibrium conductivities were extracted from the evolution of $\sigma$-time plots and used to establish the dependence of the electrical conductivity with $\mathrm{fO}_{2}$ for the two basaltic melts and different temperatures investigated. The conductivity measurements were complemented by major element and $\mathrm{FeO}$ analyses of experimental glasses in order to relate the electrical and redox state of the studied melts. For most experiments, the kinetics of the electrical response can be satisfactorily fitted by a diffusion formalism, suggesting that both oxidation and reduction reactions are kinetically limited by diffusion. The high values of the calculated diffusion coefficients $\left(\sim 10^{-9} \mathrm{~m}^{2} / \mathrm{s}\right.$ for our investigated T range) can be explained by redox mechanisms involving both oxygen and cations fluxes.

\section{EXPERIMENTS}

\subsection{Starting products}

The starting materials are two different basalts: one collected from the active vent of Pu'u' 'O'o volcano (Kilauea, Hawaii) in 2007 and a tephrite (VES9) coming from a $8^{\text {th }}$ century eruption of Mt. Vesuvius (Italy). Chemical analyses of the starting glasses are given in Table 1. Each rock was finely crushed in an agate mortar. The powder was dried and then melted in air at $1400^{\circ} \mathrm{C}$ during $\sim 1 \mathrm{~h}$. Therefore, all starting glass samples were prepared under strongly oxidizing conditions ( $\log \mathrm{fO}_{2}=-0.69$ ). Quenching resulted in bubble-free glasses that were drilled to cylinders (6 mm OD, 6.5-10 mm length), and directly loaded in the electrical conductivity cell. $\mathrm{NBO} / \mathrm{T}$ ratios (number of non-bridging oxygens divided by number of tetrahedral cations) of the two glasses, calculated considering $\mathrm{Fe}$ as both $\mathrm{FeO}$ and $\mathrm{Fe}_{2} \mathrm{O}_{3}$ and neglecting the presence of $\mathrm{Ti}$ (Mysen and Richet, 2005), are 0.56 for the Kilauea basalt and 0.55 for the Mt. Vesuvius tephrite. This underlines a similar polymerization of the tephrite and the basalt.

\subsection{Experimental setup}

All experiments were performed in a one atmosphere vertical furnace. Experimental temperatures ranged from 1200 to $1400^{\circ} \mathrm{C}$. Temperature, monitored with a Eurotherm controller, was measured by a type-S thermocouple, placed adjacent to the conductivity cell, and is known to within $+/-2^{\circ} \mathrm{C}$. The sample and the thermocouple were both located in the $3 \mathrm{~cm}$ hot spot of the 
furnace. Experimental redox conditions were controlled by the gaseous atmosphere present in the furnace. Three types of gaseous atmospheres were employed: air, pure $\mathrm{CO}_{2}$ and $\mathrm{CO}-\mathrm{CO}_{2}$ mixtures. Note that experiments using only $\mathrm{CO}_{2}$ are never performed under pure $\mathrm{CO}_{2}$, since a small quantity of $\mathrm{CO}$ is always present in the gas bottle. This small amount of $\mathrm{CO}$ (in general < a few tens of ppm) allows the gas atmosphere to act as a buffer.

For air, the tube furnace was left open to the ambient atmosphere. In contrast, for both $\mathrm{CO}_{2}$ and $\mathrm{CO}-\mathrm{CO}_{2}$ mixtures, gases were flown through the furnace (typical flow rates were $200 \mathrm{cc} / \mathrm{min})$. For $\mathrm{CO}-\mathrm{CO}_{2}$ mixtures, three different gas proportions $\left(39.7 \% \mathrm{CO}_{2} / 1.6 \% \mathrm{CO} ; 38.8 \%\right.$ $\left.\mathrm{CO}_{2} / 5.9 \% \mathrm{CO} ; 36.5 \% \mathrm{CO}_{2} / 17.5 \% \mathrm{CO}\right)$ were imposed using electronic flowmeters. Redox conditions $\left(\mathrm{fO}_{2}\right)$ were calculated from Deines et al. (1974) and directly measured using a zirconia electrolyte cell. These are referenced against the Ni-NiO equilibrium at $0.1 \mathrm{MPa}$ (Pownceby and O’Neill, 1994). For pure $\mathrm{CO}_{2}$ gas, $\Delta \mathrm{NNO}$ values range from 3.45 to 4.00 (Table 2 and 3); for $\mathrm{CO}-\mathrm{CO}_{2}$ gas mixtures, $\Delta \mathrm{NNO}$ values divide into three groups $(0.75-1.40 ;-0.35-0.45 ;-1$, Table 2 and 3), depending on the specific gas mixture imposed.

Conductivity measurements were performed using a two-electrode configuration on cylindrical samples (Gaillard, 2004; Pommier et al., 2008, Figure 1a). Glass samples of 6mm OD and $8-9 \mathrm{~mm}$ length were typically used. The inner electrode of the conductivity cell is a $1 \mathrm{~mm} \mathrm{Pt}$ wire inserted in the center of the glass sample and the external electrode is a Pt tube surrounding the sample. The drilled alumina ceramic part located at the bottom of the conductivity cell prevents the two electrodes from being in contact (Figure 1a). This configuration ensures the stability of the cell during the experiment. We assume that no convection occurs in the samples since the Rayleigh number is very small ( $<200$, Jaupart and Tait, 1995), due to the small dimensions of the samples. Thermodiffusion (Soret effect) requires the presence of a thermal gradient, which is not the case in our experiments (thermal gradient $<1-2^{\circ} \mathrm{C}$ ). At the end of the experiment, the conductivity cell and the sample were removed from the furnace and allowed to cool down under room conditions. Quenched glasses from selected conductivity charges were collected and prepared for $\mathrm{FeO}$ titration and electron microprobe analyses.

\subsection{Experimental strategy}

For each experiment at a given temperature, two $\mathrm{fO}_{2}$ steps were performed. Electrical measurements were recorded continuously until the attainment of the different equilibrium redox states. Reduction experiments consisted in an initial relatively oxidizing step followed by a final step under more reducing conditions. Oxidation experiments were the reverse of reduction 
experiments: an initial relatively reducing step was followed by a more oxidizing step. In practice, $\mathrm{fO}_{2}$ changes were obtained by switching either from air or pure $\mathrm{CO}_{2}$ to $\mathrm{CO}-\mathrm{CO}_{2}$ mixtures (reductions), or from $\mathrm{CO}-\mathrm{CO}_{2}$ mixtures to air or pure $\mathrm{CO}_{2}$ (oxidations). On the basis of voltage measurements using the zirconia probe, changing $\mathrm{fO}_{2}$ from $\mathrm{CO}-\mathrm{CO}_{2}$ to pure $\mathrm{CO}_{2}$ or air and reciprocally takes approximately a few minutes. Electrical measurements during this transition period were discarded. For oxidations in air, the conductivity cell was taken out of the furnace during the evacuation of the $\mathrm{CO}-\mathrm{CO}_{2}$ gas mixture and then replaced in the furnace at $\mathrm{T}$. Durations for each $\mathrm{fO}_{2}$ steps ranged between 90 and 1900min (Table 2).

In parallel to electrical conductivity experiments, experiments were performed in order to determine $\mathrm{Fe}^{2+} / \mathrm{Fe}^{3+}$ and other chemical changes associated with the real-time evolution of the oxygen fugacity. These experiments (designated below as analytical experiments, Table 3) used the same sample configuration and dimensions as the conductivity experiments (Figure 1b). Similarly, only one end of the glass cylinder was in contact with the furnace atmosphere. $\mathrm{T}$ and $\mathrm{fO}_{2}$ conditions were selected to match those in conductivity experiments. Samples have been rapidly quenched before redox equilibrium ${ }_{2}$ as monitored from the electrical measurements, was attained. Experimental glasses were analyzed for $\mathrm{FeO}$ titration and electron microprobe analyses.

\subsection{Acquisition and reduction of the electrical data}

In this study, electrical conductivities were derived from complex impedance spectroscopy (Roberts and Tyburczy, 1994). Electrical impedances of samples were determined at variable frequencies using a Solartron 1260 Impedance Gain Phase Analyzer, (Schlumberger Co.), equipped with Zview software package (Huebner and Dillenburg, 1995; Gaillard, 2004; Maumus et al., 2005). Each measurement consisted in a scan in frequency from $1 \mathrm{~Hz}$ to $10^{6} \mathrm{~Hz}$, lasting typically about $1 \mathrm{~min}$. For each frequency, the complex impedance was recorded. The experimental procedure, including details on the calibration process, is detailed in Pommier et al. (2009, in press). The reproducibility of the data has been demonstrated in Pommier et al. (2008).

The complex impedance, Z, can be written as the sum Z'+jZ', with Z' the real part and $Z$ " the imaginary part of $Z$ (and $j^{2}=-1$ ). The electrical response of the sample to a scan in frequency is directly observed in the Nyquist plane (Z', Z') (Figure 2), from which the value of the electrical resistance R is deduced (e.g. Huebner and Dillenburg, 1995). The non semi-circle shape of the impedance spectra is due to the fact that the samples are very conductive on the investigated $\mathrm{T}$ range, implying their electrical resistance to be smaller than the inductive effects 
$(Z "<0)$. The corresponding electrical conductivity value $\sigma$ is then deduced using the geometric factor G (Gaillard, 2004; Pommier et al., 2008):

$$
\sigma=(\mathrm{G} . \mathrm{R})^{-1}
$$

The geometric factor varies from 0.022 to $0.037 \mathrm{~m}$. The uncertainty on $\sigma$ due to error propagation of typical uncertainties on $\mathrm{R}$ ( $\mathrm{R}$ is known to $+/-0.5 \mathrm{ohm}$ in the investigated $\mathrm{T}$ range), $\mathrm{L}, \mathrm{d}_{\mathrm{ext}}$ and $\mathrm{d}_{\text {int }}$ (uncertainties on the length and the two diameters are $0.1 \mathrm{~mm}$ ) is in the range of 4.7-9\% for both our Kilauea and Mt.Vesuvius samples.

For fixed $\mathrm{T}$ and $\mathrm{fO}_{2}$ conditions and for each starting glass composition, time series measurements were conducted. They consisted in the successive acquisition of electrical measurements (each comprising a scan in frequency from $1 \mathrm{~Hz}$ to $10^{6} \mathrm{~Hz}$ ) until a stable value of $\mathrm{R}$ (and, thus, of $\sigma$ ) was reached (plateau values). The time interval between two electrical measurements ranged from $30 \mathrm{~s}$ to $1 \mathrm{hr}$ depending on the evolution of the electrical response with time: at the beginning of the experiment, small time intervals were required since the electrical response changed rapidly; on the contrary, at the end of the experiment, the small changes in the electrical response (plateau values) allowed the use of longer time spans.

\subsection{Analytical techniques}

Experimental glasses were observed optically under a microscope, in order to check for the presence of crystals and bubbles. Crystals were found to be present in some oxidation experiments performed at $1200^{\circ} \mathrm{C}$ in air for the Kilauea basalt. Results from these experiments were discarded and are not presented.

A Camebax SX-50 electron microprobe (BRGM-CNRS-Université d'Orléans) was used to analyze both the starting and the experimental glasses. Analyses were conducted at $15 \mathrm{kV}$, $6 \mathrm{nA}, 10 \mathrm{~s}$ on peak and $5 \mathrm{~s}$ on background. Both spot analyses and traverses were performed. Traverses served to evaluate the degree of iron loss from the melt to the Pt electrodes and the extent of $\mathrm{Al}^{3+}$ incorporation and diffusion from the ceramic part of the conductivity cell into the melt (Figure 1b). In the analytical charges, EMPA traverses at the gas/melt interface were used to determine the type and importance of major elements fluxes to redox changes (see Figure 1).

The FeO concentration of the starting and experimental glasses was determined by colorimetric redox titration (Gaillard et al., 2003b). With this method, the sample is dissolved in $\mathrm{HF}+\mathrm{H}_{2} \mathrm{SO}_{4}$ solution and the titration is then performed using a potassium dichromate solution. The equivalence volume provides the value of the concentration of $\mathrm{FeO}$. At least $25 \mathrm{mg}$ of 
sample powder were used for the titration in order to ensure accuracy and reproducibility. The $\mathrm{Fe}_{2} \mathrm{O}_{3}$ concentration is then calculated from:

$$
\mathrm{Fe}_{2} \mathrm{O}_{3}=1.1113 \text {. }\left(\mathrm{FeO}_{\text {tot }}-\mathrm{FeO}\right) \text {, }
$$

where $\mathrm{Fe}_{2} \mathrm{O}_{3}$ is the concentration in ferric iron (wt\%), $\mathrm{FeO}_{\text {tot }}$ is the total iron concentration (wt $\%$ ) measured by electron microprobe and $\mathrm{FeO}$ is the concentration of ferrous iron (wt\%) determined as above. $\mathrm{FeO}$ and $\mathrm{Fe}_{2} \mathrm{O}_{3}$ concentrations are then used to calculate the at. $\mathrm{Fe}^{2+} / \mathrm{Fe}^{3+}$ ratio.

\section{RESULTS}

\subsection{Melt-conductivity cell interactions}

Spot electron microprobe analyses performed in the center of the glass cylinders in most cases showed no significant changes in major element oxides in comparison with starting glass compositions. Exceptions were experiments performed at the lowest temperatures $\left(1200^{\circ} \mathrm{C}\right)$ for the Kilauea glass and at $\log \mathrm{fO}_{2}=-3.74$ and -0.69 ( $\mathrm{fO}_{2}$ in bar) (see Table 2). For those samples, the variations in major elements concentration can be explained by the crystallization of $\mathrm{Fe}-\mathrm{Ti}$ Mg oxides observed in the experimental glasses. These observations indicate that no noticeable alkali volatilization occurred during these redox experiments.

The glass-Pt interface shows no significant variations in oxide concentrations, except for $\mathrm{FeO}$, as already observed by Pommier et al. (2008). On average, iron depletions range between 2 and $7 \%$ relative. A maximum depletion of $15 \% \mathrm{FeO}$ relative affecting the melt on a distance $<500$ microns was found only for the longest experiments, for which the experimental duration exceeded the average run duration by several hours. For instance, in experiment \#5 (one of the longest experiments (Table 2), thus particularly exposed to Fe losses), the iron content close to the electrode is $\sim 4.3 \%$ mol oxide against $4.6 \%$ mol oxide in the starting glass, corresponding to a decrease of $6.5 \%$ compared to the $\mathrm{FeO}$ content. Iron depletions affect a distance in the $\mathrm{Pt}$ electrode $<100$ microns (Figure 3a), thus insignificantly modifying the iron content in the glass (Figure $3 b$ ). As a result, the bulk data (electrical conductivity and wet chemistry) will not be significantly affected by Fe losses to Pt electrodes.

The glass-alumina interface presents on most samples a nearly continuous 10-30 $\mu \mathrm{m}$ thick layer comprising Al-Mg-Fe spinel and some scattered plagioclase crystals. The contribution of these crystals to the measured electrical conductivity was evaluated according to the method exposed in Pommier et al. (2008). Calculations show that the contribution of the crystals is less than $1 \%$ of the measured conductivity. 


\subsection{Effect of oxygen fugacity and temperature on the electrical conductivity}

Electrical conductivities of the Kilauea sample measured at temperatures ranging from 1200 to $1400^{\circ} \mathrm{C}$ and covering a range of oxygen fugacities of $10^{-7.7}$ to 0.2 bar are shown in Figure 4. These are steady-state values of electrical conductivity associated with chemical equilibrium at the set $\mathrm{fO}_{2}$. A small but clearly detectable effect of oxygen fugacity on the electrical conductivity is demonstrated for each isotherm. The more reduced the melt, the higher the electrical conductivity. For comparison, no effect of $\mathrm{fO}_{2}$ on the electrical conductivity was observed in the study of Waff and Weill (1975). For both Kilauea and Vesuvius samples, the change in electrical resistance following a change in redox conditions is about a few ohms, largely exceeding the sensitivity of our measurements (better than $0.1 \%$ ) at given $\mathrm{T}$ and $\mathrm{fO}_{2}$. A small effect of composition is observed, the VES9 sample being less conductive than the Kilauea sample at 1200 and $1300^{\circ} \mathrm{C}\left(\sigma_{\mathrm{eq}}\right.$ values in Table 2$)$.

At $1300^{\circ} \mathrm{C}$, for the Kilauea sample, a change in $\mathrm{fO}_{2}$ of 8 log-units modifies the electrical conductivity of $\sim 0.2 \log$-unit (Figure 4 ). A similar effect is observed at the other investigated temperatures. For a given $\mathrm{fO}_{2}$, the electrical conductivity increases with temperature (Figure 4). The influence of temperature (increase of $\sim 1.2 \log$ units from 1200 to $1400^{\circ} \mathrm{C}$ ) appears to be similar at low and high $\mathrm{fO}_{2}$. This temperature dependency of the conductivity can be fitted by an Arrhenius equation:

$$
\sigma=\sigma_{0} \cdot \exp \left[\frac{-E a_{\sigma}}{R T}\right]
$$

with $\sigma$ the electrical conductivity (ohm.m $)^{-1}, \sigma_{0}$ the pre-exponential factor (ohm.m) $)^{-1}, \mathrm{Ea}_{\sigma}$ the activation energy $(\mathrm{J} / \mathrm{mol}), \mathrm{R}$ the universal gas constant $\left(\mathrm{J} \cdot \mathrm{K}^{-1} \cdot \mathrm{mol}^{-1}\right)$ and $\mathrm{T}$ the temperature $(\mathrm{K})$. Depending on the gas atmosphere, linear least-squares regression analysis of electrical data yields different activation energies that are presented in Table 4. Since a small effect of $\mathrm{fO}_{2}$ on $\sigma$ was detected in our experiments, we have introduced in the Arrhenian formalism the $\mathrm{fO}_{2}$ parameter. Depending on both $\mathrm{T}$ and the redox conditions, the electrical conductivity of both Kilauea and Mt. Vesuvius melts can be expressed as

$$
\sigma=\left(9 \cdot 4 \cdot 10^{3}\right) \cdot \exp \left[\frac{-117074}{R T}\right] \cdot\left(f_{O 2}\right)^{-0.03}
$$

Eq.4 reproduces measured conductivity values for all the experiments with a correlation coefficient of 0.93 and an average error of $11.6 \%$ relative. 


\subsection{Time-dependent changes in electrical conductivity during redox reaction}

At a given temperature, the time necessary to reach a stable value of the conductivity $\left(\mathrm{t}_{\mathrm{eq}}\right)$ following a change in redox state is approximately the same for a reduction under $\mathrm{CO}-\mathrm{CO}_{2}$ and an oxidation in air, while longer time spans are needed for oxidations under $\mathrm{CO}_{2}$ (Table 2). At $1200^{\circ} \mathrm{C}$, for both reduction and oxidation experiments, a stable (plateau) value of the conductivity is reached in more than 15 hours, while less than 2 hours are needed at $1400^{\circ} \mathrm{C}$.

Results of typical reduction and oxidation (in air) experiments are presented in Figure 5a and $5 \mathrm{~b}$ (experiments \#6 and \#15, respectively, Table 2). For both types of experiments, the exponential shape of the electrical response with time underlines similar reaction mechanisms and kinetics. For the experiment with pure $\mathrm{CO}_{2}$ (Figure 5c), the electrical response is more linear with time, which contrasts with the curves obtained either for oxidation in air or for reductions in $\mathrm{CO}-\mathrm{CO}_{2}$. Changing the $\mathrm{CO}_{2}$ flow rate in the furnace does not significantly change the shape of the electrical response with time (Figure 5c). The negligible effect of the gas flow rate on the kinetics of oxidation is in agreement with the observations made by Schreiber et al. (1986) using different air flow rates.

\subsection{Variations in major element chemical concentrations}

Electron microprobe traverses were performed in quenched samples from the analytical experiments to detect possible variations in major elements concentrations ( $\mathrm{Si}, \mathrm{Al}, \mathrm{Fe}, \mathrm{Mg}, \mathrm{Ca}$, $\mathrm{Na}, \mathrm{K}$ ) associated with redox changes. Traverses were performed in the longitudinal section of the samples, from the interface with gas to at least $4 \mathrm{~mm}$ inside the glass sample (Figure $1 \mathrm{~b}$ ). The spatial resolution of the probe analyses is $+/-5$ microns.

Examples of microprobe traverses are presented in Figure 6 (traverses A and B: reductions; traverse $\mathrm{C}$ : oxidation). For clarity, we state here the presence of three parts in our samples (these parts will be interpreted Part 5 in terms of redox fronts): (1) The interface zone between gas and glass $(<1 \mathrm{~mm}$ depth), from the gas/sample interface to $\xi$, is characterized by important variations in the concentration of network forming and network modifying cations in the quenched glass samples. $\xi$ ' is defined graphically and corresponds to the point at which the concentration of major elements presents an inflexion. For example, in experiment \#6-QR (traverse A), this zone presents a relative increase of 5-8\% in $\mathrm{SiO}_{2}$ and $\mathrm{Na}_{2} \mathrm{O}$ and $30 \%$ in $\mathrm{K}_{2} \mathrm{O}$ and a decrease of $5-8 \%$ in $\mathrm{MgO}$ and $\mathrm{CaO}$ to $22 \%$ in $\mathrm{FeO}$. (2) An inner zone begins at a depth $>1 \mathrm{~mm}\left(\xi^{\prime}\right)$ and extends as far as $>5 \mathrm{~mm}$ depending on experimental duration. It presents slight 
fluctuations in alkali and $\mathrm{Mg}$ and $\mathrm{Ca}$ concentrations. In experiment \#14-QO (traverse $\mathrm{C}$ ), this zone presents an increase of $4 \%$ relative in $\mathrm{CaO}$ and $\mathrm{MgO}$ and a decrease of $8.8 \%$ relative in $\mathrm{Na}_{2} \mathrm{O}$. (3) A third zone, located near the bottom of the capsule, can be detected on some profiles (traverse B). This part of the sample is identified as the unreacted melt, the compositions in this zone corresponding to the starting glass compositions. Traverses performed on samples from conductivity experiments with duration exceeding $t_{\mathrm{eq}}$ have flat profiles for all major elements (traverse D).

\subsection{FeO concentrations and evolution of glass $\mathrm{Fe}^{2+} / \mathrm{Fe}^{3+}$}

Wet chemistry was used to determine the bulk value of $\mathrm{Fe}^{2+} / \mathrm{Fe}^{3+}$ in glasses before and after most experiments (Tables 2 and 3). Analyses showed that the range of oxygen fugacities we investigated results in a range of at. $\mathrm{Fe}^{2+} / \mathrm{Fe}^{3+}$ of approximately 0.32 to 2.55 (Figure 7a).

The rate of change of $\mathrm{Fe}^{2+} / \mathrm{Fe}^{3+}$ with time was documented in both reduction and oxidation experiments. $\mathrm{Fe}^{2+} / \mathrm{Fe}^{3+}$ were measured at different time intervals following either a reduction (experiment \#4, values at $\mathrm{t}=0,300$ and $1410 \mathrm{~min}$; \#5, values at $\mathrm{t}=0,45$ and $1860 \mathrm{~min}$; \#6, values at $\mathrm{t}=0,45$ and $430 \mathrm{~min}$ ) or an oxidation (experiment \#12, values at $\mathrm{t}=0,330$ and 1380min; \#14, values at $\mathrm{t}=0,200$ and 1300min) (Tables 2 and 3). For both reduction and oxidation, the rate of change of $\mathrm{Fe}^{2+} / \mathrm{Fe}^{3+}$ is clearly nonlinear with time (Figure $7 \mathrm{~b}$ ). For example, oxidation in air of the Kilauea sample (experiment \#14) shows a decrease in at. $\mathrm{Fe}^{2+} / \mathrm{Fe}^{3+}$ from $1.64(\mathrm{t}=0)$ to 0.52 at equilibrium $\left(\mathrm{t}_{\mathrm{eq}}=1300 \mathrm{~min}\right.$, Figure $\left.7 \mathrm{~b}\right)$. The intermediate value at $\mathrm{t}=200 \mathrm{~min}$ (0.83, Table 3 ) represents a change of $\sim 80 \%$ toward the equilibrium value.

\section{DISCUSSION}

\subsection{Ferrous / ferric ratio and electrical conductivity}

\subsubsection{Why does the ferrous/ferric ratio change the electrical conductivity?}

Sodium has been identified in several studies of electrical conductivity of natural melts as the main charge carrier (Tyburczy and Waff, 1983, 1985; Gaillard, 2004; Pommier et al., 2008). The contribution of the different ionic species $\left(\mathrm{Na}^{+}, \mathrm{K}^{+}, \mathrm{Ca}^{2+}, \mathrm{Mg}^{2+}, \mathrm{Si}^{4+}, \mathrm{Al}^{3+}, \mathrm{O}^{2-}\right)$ can be discriminated using the Nernst-Einstein equation (cf Gaillard, 2004, Pommier et al., 2008): 


$$
\sigma_{i}=\frac{D_{i} \cdot q_{i}^{2} \cdot N_{i}}{k_{B} \cdot T \cdot H r} \quad \sigma_{\text {measured }}=\sum_{i} \sigma_{i}
$$

where $D_{i}$ is the coefficient of diffusion of an ion i $\left(\mathrm{m}^{2} / \mathrm{s}\right), q_{i}$ its charge $(\mathrm{C}), N_{i}$ the concentration of $\mathrm{i}\left(\mathrm{m}^{-3}\right), \mathrm{k}_{\mathrm{B}}$ is the Boltzmann constant, $\mathrm{T}$ is the absolute temperature $(\mathrm{K})$ and $\mathrm{Hr}$ the Haven ratio. $\mathrm{D}_{\mathrm{i}}$ values are taken from Chakraborty $(1995)$, calculated at $1300^{\circ} \mathrm{C}$. For the Kilauea basalt, at $1300^{\circ} \mathrm{C}$, this equation underlines that the contribution of sodium to the bulk conductivity is $\sim 80 \%$, and the contribution of potassium is only $11 \%$. This is coherent with the fact that the potassium cation is larger than $\mathrm{Na}$ and, thus, is supposed to diffuse in the melt with a slower rate than sodium. (usually, $\mathrm{D}_{\mathrm{Na}} \sim 10 . \mathrm{D}_{\mathrm{K}}$, Chakraborty, 1995). The contributions of calcium and oxygen are $3 \%$ and $4 \%$ respectively. The contributions of $\mathrm{Mg}, \mathrm{Si}$ and $\mathrm{Al}$ are $<1 \%$. These calculations underline, in particular, that the contribution of divalent cations to the measured conductivity is negligible in an alkali-rich melt. The identification of sodium as the main charge carrier in our melts implies that the changes observed in the electrical response of the samples during a redox reaction (i.e. an increase in $\sigma$ during a reduction, a decrease in $\sigma$ during an oxidation) can be related to the modifications affecting the mobility of sodium.

Other mobile species that do not control the measured electrical conductivity of the melt (such as electrons or electron holes) are not supposed to significantly affect the shape of the impedance spectra. Thus, their possible contribution to the redox mechanisms can not be observed directly using the interpretation of spectra.

Structural studies have well established that alkali charge-compensate tetrahedrally coordinated cations such as ferric iron (e.g. Thornber et al., 1980; Dickenson and Hess, 1981; Mysen, 1983; Kress and Carmichael, 1988; 1991; Lange and Carmichael, 1989; Tangeman et al., 2001; Mysen and Richet, 2005). The charge-compensation reaction can be written in a structural way (Mysen and Richet, 2005) as follows:

$$
\mathrm{SiO}_{2}+\mathrm{NaFe}^{I I I} \mathrm{O}_{2} \leftrightarrow \frac{1}{2} \mathrm{Na}_{2} \mathrm{O}+\mathrm{Fe}^{I I} \mathrm{O}+\mathrm{SiO}_{2.5}
$$

where ferric iron is charge-compensated by sodium on the left hand-side of the equation. This equilibrium enlightens the double role of sodium, being either a charge compensator (left handside of the equation) or a network modifier (NM) (right hand-side). During an oxidation, the observed decrease in electrical conductivity most likely reflects a restricted mobility of sodium, since it is structurally associated to tetrahedrally coordinated units with ferric iron. On the contrary, under more reduced conditions, less of such units are present within the melt. Thus, sodium mobility is enhanced, consistent with the observed increase in electrical conductivity. It is important to note that Eq. 5 considers only part of ferric iron as NF and part of ferrous iron as 
NM in the melt. Previous studies have shown that the presence of sodium in silicate melts promotes the formation of ferric iron (e.g. Kress and Carmichael, 1988).

\subsubsection{Time evolution of the electrical conductivity and ferrous/ferric ratio}

In our experiments, the temporal changes of both the electrical conductivity and the ferrous/ferric ratio have been monitored. To analyze these temporal evolutions, it is convenient to use the progress variable $\varepsilon$ defined as (Crank, 1975; Wendlandt, 1991):

$$
\varepsilon(\mathrm{X})=\left(\mathrm{X}(\mathrm{t})-\mathrm{X}_{0}\right) /\left(\mathrm{X}_{\mathrm{eq}}-\mathrm{X}_{0}\right)
$$

with $\mathrm{X}$ being either $\sigma$ or $\mathrm{Fe}^{2+} / \mathrm{Fe}^{3+}, \mathrm{X}(\mathrm{t})$ the value of $\mathrm{X}$ at $\mathrm{t}, \mathrm{X}_{0}$ its initial value and $\mathrm{X}_{\mathrm{eq}}$ its equilibrium value (plateau value). Both $\varepsilon(\sigma)$ and $\varepsilon\left(\mathrm{Fe}^{2+} / \mathrm{Fe}^{3+}\right)$ are compared in Figure 8 for experiments \#4 (values at $\mathrm{t}=0,300$ and $1410 \mathrm{~min}), \# 5(\mathrm{t}=0,45$ and $1860 \mathrm{~min}), \# 6(\mathrm{t}=0,45$ and 430min) and \#14 (t=0, 200 and 1300min) (Tables 2 and 3). The data fall on the straight line 1:1. This single trend underlines that, during a redox reaction, the electrical conductivity and the ferric/ferrous ratio increase or decrease with the same rate. Thus, the evolution of the electrical conductivity with time is identical to that of the redox ratio of the melt. It follows that the timedependence of the electrical response of the sample can be directly related to redox changes within the melt.

\subsection{Determination of a bulk diffusion coefficient and transport properties}

The experimental arrangement used in this study (Figure 1) is compatible with the mathematical model of the diffusion process applied to a plane sheet (Schreiber et al., 1986). In this model, diffusion occurs in a medium bounded by two parallel planes, with a constant flux on the upper boundary. Uniform initial distribution is considered. If diffusion-limited, the evolution of the electrical conductivity in response to a change in oxygen fugacity can be described by the following solution to the equation of one-dimensional diffusion:

$$
\frac{\sigma(t)-\sigma_{\text {initial }}}{\sigma_{\text {equilibrium }}-\sigma_{\text {initial }}}=1-\sum_{n=0}^{\infty} \frac{8}{(2 n+1)^{2} \pi^{2}} \cdot \exp \left[\frac{-D(2 n+1)^{2} \pi^{2} t}{4 L^{2}}\right]
$$

with $\sigma(\mathrm{t})$ the electrical conductivity $(\mathrm{ohm} . \mathrm{m})^{-1}$ at time $\mathrm{t}(\mathrm{s}), \sigma_{\text {initial }}$ the electrical conductivity

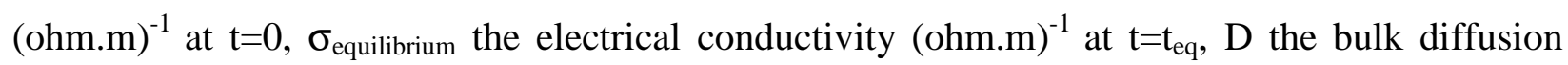
coefficient $\left(\mathrm{m}^{2} / \mathrm{s}\right)$, and $\mathrm{L}$ the length of the sample (m) (Crank, 1975, p.48). Eq.7 assumes a constant $\mathrm{D}$ as a function of time at a given temperature. The corresponding bulk redox front delimits the unreacted melt and is represented by $\xi$ " on Figure 6. 
Experimental data on the changes of conductivity with time (Figures 5a; b) were fitted using Eq. 7 and bulk diffusivity values (D) were determined. This approach proved successful for the reduction experiments performed with $\mathrm{CO}-\mathrm{CO}_{2}$ and the oxidation experiments in air (Figure $5 \mathrm{a} ; \mathrm{b})$, suggesting that both redox reactions are diffusion-limited processes. Calculated values of $\mathrm{D}$ are similar within uncertainties when determined at the same temperature, underlining that reduction and oxidation kinetics operate at the same rates (Figure 9a). In contrast, oxidation performed under $\mathrm{CO}_{2}$ is not compatible with Eq.7 and, therefore, in this case the redox evolution is not rate-limited by diffusion (Figure 5c). In general, redox studies have been performed assuming that the processes studied are diffusion-limited. Our approach, consisting in following redox processes in real-time and with high accuracy, suggests that the nature of the gaseous oxygen carrier influences the redox kinetics and that, the redox processes under $\mathrm{CO}_{2}$ are probably not diffusion-limited. A linear evolution of the electrical conductivity with time is clearly observed, independently of the gas flux. A few previous studies have reported non-diffusionlimited processes during redox experiments under pure $\mathrm{CO}_{2}$ (Goldman, 1983; Goldman and Gupta, 1983; Schreiber et al., 1986; Roskosz et al., 2008). Most likely, the linear changes shown in Figure $5 \mathrm{c}$ reveal a specific rate-limiting process at the gas/melt interface (e.g. surface diffusion, chemical reaction).

The temperature dependence of the calculated D values follows an Arrhenian dependence (Figure 9a):

$$
D=D_{0} \cdot \exp \left[\frac{-E a_{D}}{R T}\right]
$$

with $\mathrm{Ea}_{\mathrm{D}}$ the activation energy $(\mathrm{kJ} / \mathrm{mol})$ and $\mathrm{D}_{0}$ the pre-exponential factor $\left(\mathrm{m}^{2} / \mathrm{s}\right)$. Our diffusivity values range from $10^{-9}$ to $10^{-8} \mathrm{~m}^{2} / \mathrm{s}$ for the $\mathrm{T}$ range $1200-1400^{\circ} \mathrm{C}$. These diffusion rates are comparable to typical alkali self-diffusion coefficients in basaltic melts from literature (Henderson, 1985; Chakraborty, 1995). Comparable diffusivity values are also calculated using the Nernst-Einstein equation (Eq. 5) and assuming that sodium is the unique charge carrier in the melt (i.e. $\sigma_{\text {equilibrium }}=\sigma_{\mathrm{Na}+}$ ). These two points underline the importance of the role of sodium in the investigated redox processes. However, the high values of activation energy $\left(E_{D} \geq 200 \mathrm{~kJ} / \mathrm{mol}\right.$, Figure 9a, b) calculated from Eq.8 are similar to activation energy for alkali-Earth elements (LaTourrette et al., 1996; Chakraborty, 1995) and oxygen self-diffusion (Lesher et al., 1996; Tinker et al., 2003) in silicate melts and is higher than the one expected for alkali self-diffusion ( 100kJ/mol, Chakraborty, 1995) (see also Appendix 2).

Activation energy and pre-exponential term for redox kinetics in melts obtained in this study and previous ones (Lawless and Wedding, 1970; Sasabe and Goto, 1974; Doremus, 1960; 
Dunn, 1983; Semkow and Haskin, 1985; Schreiber et al., 1986; Cook et al., 1990; Wendlandt, 1991; Cooper et al., 1996; Cook and Cooper, 2000; Everman and Cooper, 2003) are plotted in a compensation plot (Figure $9 b)$. The compensation law for natural melts $\left(\mathrm{r}^{2}>0.91\right)$ is:

$$
\mathrm{Ea}_{\mathrm{D}}=11.84 . \mathrm{LnD}_{0}+293.5
$$

The single trend stresses that the kinetics of redox changes in our study is essentially similar to that found in other studies.

Figure 9c presents the calculated oxidation-reduction rates as a function of oxygen fugacity variations. Variations of $\mathrm{fO}_{2}$ (initial $\mathrm{fO}_{2}-$ final $\mathrm{fO}_{2}$ ) are directly correlated to variations of the driving potential (or driving force, $\Delta \mu$ ) of the redox reaction occurring in the melt:

$$
\Delta \mu=\Delta\left(\text { R.T.Ln } \mathrm{fO}_{2}\right)
$$

No clear evidence of such a dependence of D values is observed for our experiments, even for the experiments at $1300^{\circ} \mathrm{C}$ that involve the largest $\left|\Delta \log \mathrm{fO}_{2}\right|$ (from 2 to 7 ). Figure $9 \mathrm{c}$ suggests that a possible dependence of $\mathrm{D}$ to variations of $\mathrm{fO}_{2}$ is too weak to be discriminated and that the high $\mathrm{D}$ values calculated in our redox experiments can not be explained by variations of the driving potential.

\subsection{Redox dynamics}

Redox mechanisms are proposed on the basis of conductivity measurements, chemical titrations, mass balance calculations, EMPA profiles and previous redox studies. EMPA profiles (Figure 6) show complex pattern of chemical zonation, which are however difficult to interpret in terms of cation fluxes, since a change in cation content can be caused by the dilution effect of other mobile species. Microprobe traverses were nevertheless used to detect an internal reaction front, $\xi$ ', whose location is presented in Figure 6. $\xi$ ' corresponds to an inflexion point in the chemical profiles.

$\xi$ 'is different from the bulk reaction front $\xi$ " provided by bulk diffusion coefficients (Eq.7). The identification of these two fronts stresses out two different steps of one reaction or two different reactions that are all part of the redox mechanisms. Position of $\xi$ ' at $\mathrm{t}$ corresponds to diffusivities in the melt of $\sim 10^{-11} \mathrm{~m}^{2} / \mathrm{s}$ for both reductions and oxidations, using the following equation:

$$
\mathrm{D}=\mathrm{L}^{2} / \mathrm{t}
$$

D the diffusion coefficient $\left(\mathrm{m}^{2} / \mathrm{s}\right), \mathrm{L}$ defining the distance between $\xi$, and the gas/melt interface (m), t the time of quenching (s). These values are much lower than bulk diffusivities deduced 
from conductivity measurements using Eq.7 $\left(10^{-9}-10^{-8} \mathrm{~m}^{2} / \mathrm{s}\right)$. The progression rate of $\xi$, compares well with self-diffusivities of $\mathrm{O}$ and $\mathrm{Si}$ in basaltic liquid (Canil and Muehlenbachs, 1990; Lesher et al., 1996) and with the rate laws derived by Cooper and coworkers using similar methodologies (identification of a migration front of cations). Another argument for $\mathrm{O}$ and $\mathrm{Si}$ mobility in the interface zone is that our $\mathrm{Ea}_{\mathrm{D}}$ values are comparable with Ea values from viscosity measurements (Giordano et al., 2008), which are based on the Si-O bounds (and oxygen mobility). The mobility of $\mathrm{Si}$ as $\mathrm{Si}-\mathrm{O}$ has been previously suggested by Terai and Oishi, 1977 . This suggests that $\mathrm{Si}-\mathrm{O}$ mobility defines the progression of $\xi^{\prime}$, which is not considered in the model of Cooper et al. (1996b). Si-O species are less mobile than sodium and they are not charged species. Thus, they do not directly influence the observed changes in conductivity. However, their migration could influence the charge carrier mobility. The effect of Si-O on $\sigma$ would thus be indirect and part of the cations mobility can be interpreted as a consequence of SiO migrations.

The progression rate of $\xi$ ', graphically deduced from EMPA profiles, is slower than the progression rate of $\xi$ ', determined using electrical measurements and corresponding to the rate of the evolution of the redox ratio. This implies that apparent divalent cation migration and $\mathrm{Fe}^{2+} / \mathrm{Fe}^{3+}$ changes are kinetically decoupled. This was not observed in previous studies that proposed redox mechanisms controlled by divalent cations mobility, since the time-evolution of the $\mathrm{Fe}^{2+} / \mathrm{Fe}^{3+}$ ratio was not monitored in these studies (e.g., Cooper et al., 1996b). The rate laws of the evolution of $\xi$ " observed in our study are comparable to the kinetics of iron redox reactions in silicate melts (e.g. Magnien et al., 2008).

A schematic drawing of reduction and oxidation dynamics at the scale of the sample are proposed in Figure 10. The model considers the main fluxes of mobile species and, in particular, the rate-limiting ionic fluxes that probably hide other minor processes occurring at the same time. This implies that metastable structures that are probably formed during the initial stages of the redox reaction are not represented. We assume that the influence of these structures on the calculations of diffusion coefficients of mobile species during the redox reaction can be neglected. The model used to represent the evolution of a redox reaction is based on a Fickian formalism. This simple approach can be used as a first approximation which allows us to explain the $D$ values in terms of major cation fluxes. The fluxes of cations $\left(\mathrm{j}_{\mathrm{i}}\right)$ between the free surface ( $\xi_{0}$ ) and the bulk reaction front $\xi$ " have been analyzed using the Fick-Einstein equation applied to ionic materials (Cooper et al., 1996a): 


$$
j_{i}=\frac{x_{i} \cdot D_{i}}{\lambda_{i} \cdot V m \cdot \Delta \xi} \cdot \ln \left(\frac{f_{O 2}^{\xi=0}}{f_{O 2}^{\xi "}}\right)
$$

with $\mathrm{x}_{\mathrm{i}}$ the molar fraction of the cation $\mathrm{i}\left(\mathrm{Na}^{+}, \mathrm{K}^{+}, \mathrm{Ca}^{2+}, \mathrm{Mg}^{2+}, \mathrm{Fe}^{2+}\right), \mathrm{D}_{\mathrm{i}}$ its diffusion coefficient $\left(\mathrm{m}^{2} / \mathrm{s}\right), \lambda_{\mathrm{i}}$ the stoechiometric coefficient, $\mathrm{Vm}$ the molar volume of the reduced or oxidized melt $\left(\mathrm{m}^{3} / \mathrm{mol}\right), \Delta \xi$ the distance between the free surface and the bulk reaction front $(\mathrm{m})$, and $\mathrm{f}_{\mathrm{O} 2}$ the oxygen fugacity $(\mathrm{Pa})$ (with the superscript indicating location). The $\mathrm{f}_{\mathrm{O} 2}$ ratio expresses the difference in oxygen chemical potential between reacted and unreacted melt (i.e. between $\xi_{0}$ and $\xi ")$. D values for cations come from the literature (Henderson et al., 1985; Chakraborty, 1995; Lesher et al., 1996) and are assumed to be constant during the redox reaction. $\lambda_{\mathrm{i}}$ values correspond to the number of mol of cation in the oxidized form (molecular form) that is produced when one mole of $\mathrm{O}_{2}$ reacts with cation i. Details on the calculations of $\lambda_{\mathrm{i}}$ are presented in Appendix 3. $\Delta \xi$ is calculated using Eq. 10 with $\mathrm{D}=\mathrm{D}_{\text {bulk }}$ (from Eq.7) and $\mathrm{t}=\mathrm{t}_{\text {quench }}$ (Table3).

In the case of redox mechanisms driven by a single kind of ionic species (e.g. divalents cations, Cooper et al., 1996), the motion of the redox front into the melt with time can be written as follows:

$$
\frac{d \Delta \xi}{d t}=\lambda_{M^{2+}} \cdot j_{M^{2+}} \cdot V m=\frac{x_{M^{2+}} \cdot D_{M^{2+}}}{\Delta \xi} \cdot \ln \left(\frac{f_{O 2}^{\xi_{0}}}{f_{O 2}^{\xi "}}\right)
$$

$\mathrm{M}^{2+}$ being a divalent cation. These mechanisms were observed for experimental timescales of a few seconds or minutes (Cooper et al., 1996b; Everman and Cooper, 2003) or in the glass region (Cooper et al., 1996a; Cook and Cooper, 2000). As discussed before, at the timescale of our experiments (i.e. several hours), redox dynamics in the basaltic melts probably not come down to the only divalent cation fluxes. Our study suggests that oxygen, and alkalis also probably contribute significantly to the advancement of the bulk redox front $\xi "$. The time-evolution of the redox front becomes:

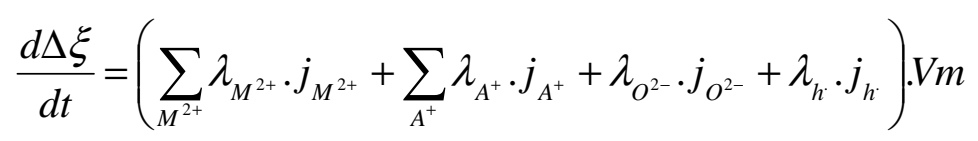

with $\mathrm{M}^{2+}=\mathrm{Ca}^{2+}, \mathrm{Mg}^{2+}, \mathrm{Fe}^{2+}, \mathrm{A}^{+}=\mathrm{Na}^{+}, \mathrm{K}^{+}$and he electron holes. $\lambda_{\mathrm{M} 2+}=\lambda_{\mathrm{A}+}=2, \lambda_{\mathrm{O}_{2}}=2, \lambda_{\mathrm{h} .}=4$ (Appendix 3).

$\mathrm{Si}^{4+}$ and $\mathrm{Al}^{3+}$ ions are not considered in the present redox model. No evidence of free $\mathrm{Si}^{4+}$ ions has been found in previous studies (Bockris et al., 1952; Semkow and Haskin, 1985). The very high bond energy of Si-O ( 373kJ/mol, Bockris et al., 1952) strengthens the low probability for $\mathrm{Si}^{4+}$ ions to exist in a free state capable of migration within the melt. A significant role of aluminium in redox mechanisms has never been observed, to our knowledge. 
The fluxes of considered cations are calculated using Eq.12 and the flux of oxygen can be expressed by:

$$
j_{O^{2-}}=\frac{x_{O^{2-}} \cdot D_{O^{2-}}}{2 \cdot V m \cdot \Delta \xi} \cdot \ln \left(\frac{f_{O 2}^{\xi=0}}{f_{O 2}^{\xi "}}\right)
$$

where $x_{O^{2-}}=\frac{n_{\text {oxygen }}}{n_{\text {total }}} \cdot \mathrm{n}_{\text {oxygen }}$ corresponds to the total oxygen content of the melt. $\mathrm{n}_{\text {total }}$ corresponds to the amount of oxygen and cations. Both $\mathrm{n}_{\text {oxygen }}$ and $\mathrm{n}_{\text {total }}$ are determined by mass balance calculations. As in Cooper et al. (1996a), the flux of electron holes $\left(\mathrm{j}_{\mathrm{h}}\right.$.) was calculated using the charge neutrality condition:

$$
\sum_{i} z_{i} \cdot j_{i}=\left(\sum_{\text {cations }} z_{\text {cations }} \cdot j_{\text {cations }}\right)-2 j_{O^{2-}}+j_{h^{*}}=0
$$

where $\mathrm{z}_{\text {cations }}$ corresponds to the valence of the cations. Calculation of $\mathrm{d} \xi / \mathrm{dt}$ using Eq. 14 for the quenched experiments yields similar values for oxidation and reduction at the same temperature. For instance, $\mathrm{d} \xi / \mathrm{dt}=2 \cdot 2 \cdot 10^{-7} \mathrm{~m} / \mathrm{s}$ and $8 \cdot 10^{-8} \mathrm{~m} / \mathrm{s}$ for experiments \#12-QO and \#4-QR, respectively (Table 3).

As shown in Figure 10, the incorporation (oxidation) or release (reduction) of oxygen leads to competitive mechanisms between the different ionic species. At the internal front $\xi$, variations of $\mathrm{Na}^{+}$mobility are related to the reduction or oxidation of ferric or ferrous iron, respectively. In oxidation and reduction experiments, the reacted melt (delimited by front $\xi$ ") is characterized by opposite fluxes of oxygen and cations. The smaller amounts of networkmodifier cations compared to oxygen anions imply electron holes to charge-balance $\mathrm{O}^{2-}$ fluxes.

According to Eq. 12 and 14, the evolution of the redox front as a function of time can be written as follows:

$$
\Delta \xi . d \Delta \xi=\sum_{i} A i . d t \quad \text { with } \quad A i=x_{i} \cdot D_{i} \cdot \ln \left(\frac{f_{O 2}^{\xi_{0}}}{f_{O 2}^{\xi^{\prime \prime}}}\right)=\lambda_{i} \cdot j_{i} \cdot V m
$$

Integration of Eq. 17 leads to the following parabolic kinetic law: 


$$
\int_{\xi_{0}=0}^{\xi^{\prime \prime}} \Delta \xi . d \Delta \xi=\sum_{i} A i \cdot \int_{t_{0}=0}^{t} d t \Rightarrow \frac{\xi^{\prime \prime 2}}{t}=2 \cdot \sum_{i} A i
$$

The term $\frac{\xi^{\prime 2}}{t}$ (in $\mathrm{m}^{2} / \mathrm{s}$ ) corresponds to a bulk diffusion coefficient associated to the redox reaction and, thus, should be compared to the values of the redox front diffusion coefficient $\mathrm{D}_{\text {bulk }}$ calculated using Eq. 7. Numerical calculations yield values of $\frac{\xi^{\prime \prime 2}}{t}$ similar to the measured $D_{\text {bulk }}$ (Eq. 7 and Figure 9a): between $\sim 1.8 .10^{-9} \mathrm{~m}^{2} / \mathrm{s}$ at $1200^{\circ} \mathrm{C}$ and $\sim 4.5 .10^{-9} \mathrm{~m}^{2} / \mathrm{s}$ at $1300^{\circ} \mathrm{C}$. This implies that the evolution of the redox front with time can be explained by a mechanism involving cooperative fluxes of cations, oxygen and electron holes. The contribution of cations and oxygen to the redox mechanisms are in agreement with the high activation energy values calculated using Eq.8 (>200kJ/mol). The calculated fluxes of cation (Eq. 12) needed to match the global redox kinetics are however small $\left(10^{-11}-10^{-13} \mathrm{~mol} \cdot \mathrm{m}^{-2} \cdot \mathrm{s}^{-1}\right)$. This is consistent with the absence of noticeable cations variations in the inner part of the quenched samples using EMPA profiles (distance $>\xi$, , see Figure 6). Highest values of fluxes correspond to oxygen and sodium $\left(\sim 10^{-11}\right.$ mol. $\mathrm{m}^{-2} \cdot \mathrm{s}^{-1}$, whereas fluxes of potassium and divalent cations are $\left.\sim 10^{-12}-10^{-13} \mathrm{~mol} \cdot \mathrm{m}^{-2} \cdot \mathrm{s}^{-1}\right)$, implying that these two species are the main contributors to the redox dynamics.

The mechanism that occurs to finally provide a uniform chemistry (e.g. from profile $\mathrm{C}$ to $\mathrm{D}$ in Figure 6) probably consists in a reequilibration of electrochemical potential. This reequilibration would correspond, in the case of our samples, to a coupled exchange of moving back alkali and divalent cations.

\section{CONCLUSION AND REDOX EXCHANGES IN NATURE}

Electrical measurements have been used to investigate in real-time redox kinetics in basaltic liquids after $\mathrm{fO}_{2}$-step changes. Data were recorded between 1200 and $1400^{\circ} \mathrm{C}$, on the $\mathrm{fO}_{2}$ range $10^{-8}-0.2$ bars. Electrical conductivity was found to increase slightly with decreasing $\mathrm{fO}_{2}$. A modified Arrhenius law expressing the dependence of the electrical conductivity to both $\mathrm{fO}_{2}$ and $\mathrm{T}$ has been proposed. The evolution of electrical conductivity, based on sodium mobility, reproduces the evolution of the ferric/ferrous ratio of the melt. Reduction under $\mathrm{CO}-\mathrm{CO}_{2}$ and oxidation in air are diffusion-limited processes, whereas a gas-melt interface reaction probably rate-limit oxidation under pure $\mathrm{CO}_{2}$. The high diffusion rates $\left(10^{-9}-10^{-8} \mathrm{~m}^{2} / \mathrm{s}\right)$ and activation 
energies (>200 kJ/mol) calculated on the investigated $\mathrm{T}$ range in basaltic melts can be explained by redox mechanisms involving co-operative alkali, divalent cations and oxygen fluxes.

According to Gaillard et al. (2003a), attainment of redox equilibrium in hydrogen-bearing melts was found to be rate-controlled by $\mathrm{H}_{2}$ fluxes in the melt at a reaction front corresponding to:

$$
\mathrm{H}_{2}+2 \mathrm{FeO}_{1.5}=2 \mathrm{FeO}+\mathrm{H}_{2} \mathrm{O}
$$

This statement was particularly supported by the fact that $\mathrm{H}_{2}$ migration in the melt is much faster than divalent cations migration calculated after Cooper and coworkers. For example, at $1300^{\circ} \mathrm{C}$, at $\mathrm{f}_{\mathrm{H} 2}=1$ and $100 \mathrm{bar}$, Gaillard et al. (2003a) calculated reaction rates of iron redox changes in hydrous magmas of $\sim 2.5 .10^{-12}$ and $10^{-9} \mathrm{~m}^{2} / \mathrm{s}$, respectively, while extrapolation of D values of Cooper et al. (1996a) at the same $\mathrm{T}$ in basaltic melts provides a reaction rate of $\sim 4.10^{-13}$ $\mathrm{m}^{2} / \mathrm{s}$. Our results, however, indicate reaction rates of $10^{-9}-10^{-8} \mathrm{~m}^{2} / \mathrm{s}$ at $1300^{\circ} \mathrm{C}$, which exceed well the rates extrapolated from Cooper et al (1996a). The hydrogen-dominated mechanisms exposed in Gaillard et al. (2003a) will therefore not necessarily operate in basaltic systems because cooperative motions of oxygen and cations revealed in our study can be faster than exchanges rate-limited by $\mathrm{H}_{2}$ fluxes. Only for $\mathrm{fH}_{2}$ values exceeding 50 bars, reaction rates are nearly equivalent, implying that the mechanisms of Gaillard et al. might affect basalts under specific conditions such as in moderately oxidized mantle wedge (water-rich at NNO). However, in most conditions experienced by basaltic liquids (i.e. moderately hydrated), the mechanism we revealed in our study should dominate the kinetics of redox potential re-equilibration.

\section{Acknowledgements}

This paper is part of the $\mathrm{PhD}$ of $\mathrm{A}$. Pommier. The authors are grateful to T. Orr for providing Kilauea sample and R. Cioni for Mt Vesuvius sample. R.F. Cooper, M. Roskosz and an anonymous reviewer are warmly thanked for helpful comments and fruitful discussions. P. Ulmer is acknowledged for his careful editorial work. This study has been supported by the French national agency for research, ANR JC05-42707 (Electrovolc) attributed to F. Gaillard.

\section{References}


Beerkens, R.G.C., and H. de Waal (1990), Mechanism of oxygen diffusion in glassmelts containing variable-valence ions, J. Am. Cearm. Soc., 73 (7), 1857-1861.

Behrens, H., and F. Gaillard (2006), Geochemical aspects of melts: volatiles and redox behavior, Elements, 2 (5), 275-280.

Bockris, J. O'M., J.A. Kitchener, S. Ignatowitcz, and J. W. Tomlinson (1952), Electric conductance in liquid silicates, Trans. Farad. Soc., 48 (6), 536-548.

Botcharnikov, R. E., J. Koepke, F. Holtz, C. McCammon, and M. Wilke (2005), The effect of water activity on the oxidation and structural state of $\mathrm{Fe}$ in a ferro-basaltic melt, Geochim. Cosmochim. Acta, 69 (21), 5071-5085.

Canil, D. and K. Muehlenbachs (1990), Oxygen diffusion in an Fe-rich basalt melt, Geochim. Cosmochim. Acta, 54, 2947-2951.

Carmichael, I. S. E. (1991), The redox states of basic and silicic magmas-a reflection of their source region, Contrib. Mineral. Petrol., 106 (2), 129-141.

Carmichael, I. S. E. and M. S. Ghiorso (1990), The effect of oxygen fugacity on the redox state of natural liquids and their crystallizing phases, Modern source of igneous petrology: understanding magmatic processes, vol. 24, 191-212.

Chakraborty, S., (1995), Diffusion in silicate melts, in Structure, dynamics and properties of silicate melts, Reviews in Mineralogy, vol. 32, 411-503.

Cook, G. B., R. F. Cooper and T. Wu (1990), Chemical diffusion and crystalline nucleation during oxidation of ferrous iron-bearing magnesium aluminosilicate glass, J. NonCryst. Solids, 120, 207-222.

Cook, G. B., and R. F. Cooper (2000), Iron concentration and the physical processes of dynamic oxidation in an alkaline earth aluminosilicate glass, Am. Mineralogist, 85, 397-406.

Cooper, R. F., J. B. Fanselow, and D. B. Poker (1996a), The mechanism of oxidation of a basaltic glass: chemical diffusion of network-modifying cations, Geochim. Cosmochim. Acta, 60(17), 3253-3265.

Cooper, R. F., J. B. Fanselow, J. K. R. Weber, D. R. Merkley, and D. B. Poker (1996b), Dynamics of oxidation of a Fe2+-bearing aluminosilicate (basaltic) melt, Science, 274, 11731176.

Crank, J. (1975), The Mathematics of Diffusion, 2nd ed., 440 pp., Claredon, Oxford, U.K.

Deines, P., R. H. Nafziger, G. C. Ulmer, and E. Woermann (1974), Temperature-oxygen fugacity tables for selected gas mixtures in the system $\mathrm{C}-\mathrm{H}-\mathrm{O}$ at one atmosphere total pressure, Bull. Earth and Mineral Sciences, Experiment Station, 88, 130pp., University Park, Pennsylvania, USA.

Dickenson, M.P., and P.C. Hess (1981), Redox equilibria and the structural role of iron in alumino-silicate melts, Contrib. Mineral. Petrol., 78, 352-357.

Doremus, R. H. (1960), Diffusion of oxygen from contracting bubbles in molten glass, $J$. Amer. Ceram. Soc., 43(12), 655-661.

Dunn, T. (1982), Oxygen diffusion in three silicate melts along the join diopsideanorthite, Geochim. Cosmochim. Acta, 46, 2293-2299.

Dunn, T. (1983), Oxygen chemical diffusion in three basaltic liquids at elevated temperatures and pressures, Geochim. Cosmochim. Acta, 47, 1923-1930.

Dunn, T. and C. M. Scarfe (1986), Variation of the chemical diffusivity of oxygen and viscosity of an andesite melt with pressure at constant temperature, Chem. Geology, 54, 203-215.

Everman, R. L. A. and R. F. Cooper (2003), Internal reduction of an iron-doped magnesium aluminosilicate melt, J. Amer. Ceram. Soc., 86(3), 487-494.

Frost, D. J., and C. A. McCammon (2008), The redox state of the Earth's mantle, Annual Rev. Earth and Planet. Sciences, 36, 389-420.

Gaillard, F., B. Scaillet and M. Pichavant (2002), Kinetics of iron oxidation-reduction in hydrous silicic melts, Am. Mineralogist, 87(7), 829-837. 
Gaillard, F., B. Schmidt, S. Mackwell and C. McCammon (2003a), Rate of hydrogen-iron redox exchange in silicate melts and glasses, Geochim. Cosmochim. Acta, 67 (13), 2427-2441.

Gaillard, F., M. Pichavant, and B. Scaillet (2003b), Experimental determination of activities of $\mathrm{FeO}$ and $\mathrm{Fe} 2 \mathrm{O} 3$ components in hydrous silicic melts under oxidizing conditions, Geochim. Cosmochim. Acta, 67 (22), 4389-4409.

Gaillard, F. (2004), Laboratory measurements of electrical conductivity of hydrous and dry silicic melts under pressure, Earth Planet. Sci. Lett., 218(1-2), 215-228, doi:10.1016/S0012821X(03)00639-3.

Gaillard, F., and G. Iacono-Marziano (2005), Electrical conductivity of magma in the course of crystallization controlled by their residual liquid composition, J. Geophys. Res., 110, B06204, doi:10.1029/ 2004JB003282.

Gaillard, F., and B. Scaillet (2009), The sulfur content of volcanic gases on Mars, Earth Planet. Sci. Lett., 279, 34-43.

Giordano, D., J. K. Russell, and D. B. Dingwell (2008), Viscosity of magmatic liquids: A model, Earth Planet. Sci. Lett., 271(1-4), 123-134.

Goldman, D. S. (1983), Oxidation equilibrium of iron in borosilicate glass, J. Amer. Ceram. Soc., 66(3), 205-209.

Goldman, D. S. and P. K. Gupta (1983), Diffusion-controlled redox kinetics in a glassmelt, J. Amer. Ceram. Soc., 66(3), 188-190.

Henderson, P., J. Nolan, G. C. Cunningham, and R. K. Lowry (1985), Structural control and mechanisms of diffusion in natural silicate melts, Contrib. Mineral. Petrol., 89(2 - 3), 263 272, doi:10.1007/BF00379459.

Herd, C. D. K., L. E. Borg, J. H. Jones, and J. J. Papike (2002), Oxygen fugacity and geochemical variations in the martian basalts: implications for martian basalt petrogenesis and the oxidation state of the upper mantle of Mars, Geochim. Cosmochim. Acta, 66(11), 2025-2036.

Herd, C. D. K. (2008), Basalts as probes of planetary interior redox state, Reviews in Mineralogy and Geochemistry, 68, 527-553.

Huebner, J. S., and R. G. Dillenburg (1995), Impedance spectra of hot, dry silicate minerals and rock: Qualitative interpretation of spectra, Am. Mineral., 80(1- 2), 46-64.

Jaupart, C., and Tait, S. (1995), Dynamics of differentiation in magma reservoirs, , $J$. Geophys. Res., 100, B9: 17615-17656.

Kress, V. C., and I. S. E. Carmichael (1988), Stoichiometry of the iron oxidation, Am. Mineral., 73(11-12), 1267-1274.

Kress, V. C., and I. S. E. Carmichael (1991), The compressibility of silicate liquids containing $\mathrm{Fe} 2 \mathrm{O} 3$ and the effect of composition, temperature, oxygen fugacity and pressure on their redox states, Contrib. Mineral. Petrol., 108(1-2), 82-92.

Lange, R. A. and I. S. E. Carmichael (1989), Ferric-ferrous equilibria in Na2O-FeOFe2O3-SiO2 melts - effects of analytical techniques on derived partial molar volumes, Geochim. Cosmochim. Acta, 53(9), 2195-2204.

La Tourrette, T., G.J. Wasserburg and A.J. Fahey (1996), Self diffusion of $\mathrm{Mg}, \mathrm{Ca}, \mathrm{Ba}$, $\mathrm{Nd}, \mathrm{Yb}, \mathrm{Ti}, \mathrm{Zr}$, and U in haplobasaltic melt, Geochim. Cosmochim. Acta, 60(8), 1329-1340.

Lawless, W. N., and B. Wedding (1970), Photometric study of the oxygen diffusivity in aluminosilicate glass, J. Appl. Phys., 41, 1926-1929.

Lesher, C.E., R.L. Hervig and D. Tinker (1996), Self diffusion of network formers (silicon and oxygen) in naturraly occurring basaltic liquid, Geochim. Cosmochim. Acta, 60(3), 405-413.

Magnien, V., D. R. Neuville, L. Cormier, J. Roux, J.-L. Hazemann, D. de Ligny, S. Pascarelli, I. Vickridge, O. Pinet, and P. Richet (2008), Kinetics and mechanisms of iron redox reactions in silicate melts: the effects of temperature and alkali cations, Geochim. Cosmochim. Acta, 72(8), 2157-2168 . 
Maumus, J., N. Bagdassarov, and H. Schmeling (2005), Electrical conductivity and partial melting of mafic rocks under pressure, Geochim. Cosmochim. Acta, 69(19), 4703-4718, doi:10.1016/j.gca.2005.05.010.

Moretti, R., and P. Papale (2004), On the oxidation state and volatile behavior in multicomponent gas-melt equilibria, Chem. Geology, 213, 265-280.

Moynihan, C.T., Description and analysis of electrical relaxation data for ionically conducting glasses and melts, Solid State Ionics 105 (1998), 175-183.

Muelhenbachs, K. and I. Kushiro (1974), Oxygen isotope exchange and equilibrium of silicates with $\mathrm{CO}_{2}$ or $\mathrm{O}_{2}$, Carnegie Instn Geophys. Laboratory, 73, 232-236.

Mysen, B. O. (1983), The structure of silicate melts, Ann. Rev. Earth Planet. Sci., 11, 75-

97.

Mysen, M. O., and P. Richet (2005), Silicate Glasses and Melts, Properties and Structure, 544 pp., Elsevier, Amsterdam, Netherlands.

Pettersen, C., and R. F. Cooper (2008), Float-reaction between liquid bronze and magnesium aluminosilicate and $\mathrm{ZnO}$-doped magnesium aluminosilicate glass-ceramic-forming glassmelts, J. Non-Cryst. Solids, 354, 3194-3206.

Pommier, A., F. Gaillard, M. Pichavant, and B. Scaillet (2008), Laboratory measurements of electrical conductivities of hydrous and dry Mount Vesuvius melts under pressure, J. Geophys. Res., 113, B05205, doi:10.1029/2007JB005269.

Pommier, A., M. Malki, F. Gaillard, and M. Pichavant (2009), Methodological reevaluation of the electrical conductivity of silicate melts, Am. Mineralogist, accepted.

Pownceby and O'Neill (1994), Thermodynamic data from redox reactions at high temperatures. IV. Calibration of the Re-ReO2 oxygen buffer from EMF and NiO+Ni-Pd redox sensor measurements, Contrib. Mineral. Petrol., 118, 130 - 137.

Reid, J. E., B. T. Poe, D. C. Rubie, N. Zotov, and M. Wiedenbeck (2001), The selfdiffusion of silicon and oxygen in diopside $\left(\mathrm{CaMgSi}_{2} \mathrm{O}_{6}\right)$ liquid up to $15 \mathrm{GPa}$, Chem. Geology, $174,77-86$.

Righter, K., and M. J. Drake (1996), Core formation in the Earth's Moon, Mars and Vesta, Icarus, 124, 513-529.

Roberts, J. J., and J.A. Tyburczy (1994), Frequency-dependent electrical properties of minerals and partial melts, Surveys in Geophysics, 15(2), 239-262.

Roselieb, K., and A. Jambon (2002), Tracer diffusion of $\mathrm{Mg}, \mathrm{Ca}, \mathrm{Sr}$ and $\mathrm{Ba}$ in aluminosilicate melts, Geochim. Cosmochim. Acta, 66, 109-123.

Roskosz, M., M. J. Toplis, D. R. Neuville, and B. O. Mysen (2008), Quantification of the kinetics of iron oxidation in silicate melts using Raman spectroscopy and assessment of the role of oxygen diffusion, American Mineralogist, 93(11-12), 1749-1759.

Sasabe, M., and K. S. Goto (1974), Permeability, diffusivity, and solubility of oxygen gas in liquid slag, Metall. Transactions, 5, 2225-2233.

Semkow, K. W. and L. A. Haskin (1985) Concentrations and behavior of oxygen and oxide ion in melts of composition CaO-MgO-XSiO ${ }_{2}$, Geochim. Cosmochim. Acta, 49(9), 18971908.

Schmalzried, H. (1984), Oxide solid-solutions and its internal reduction reactions, H. Ber. Bunsen-Ges. Phys. Chem., 88, 12, 1186-1191.

Schreiber, H. D., and S. J. Kozac, A. L. Fritchman, D.S. Goldman, and H. A. Schaeffer (1986), Redox kinetics and oxygen diffusion in a borosilicate melt, Physics Chem. Glasses, 27(4), 152-177.

Tangeman, J. A., R. Lange, and L. Forman (2001), Ferric-ferrous equilibria in $\mathrm{K}_{2} \mathrm{O}-\mathrm{FeO}-$ $\mathrm{Fe}_{2} \mathrm{O}_{3}-\mathrm{SiO}_{2}$ melts, Geochim. Cosmochim. Acta, 65(11), 1809-1819.

Thornber, C. R., P. L. Roeder, and J. R. Foster (1980), The effect of composition on the ferric-ferrous ratio in basaltic liquids at atmospheric pressure, Geochim. Cosmochim. Acta, 44, $525-532$. 
Tinker, D., C. E. Lesher, and I. Hutcheon (2003), Self-diffusion of Si and O in diopsideanorthite melt at high pressures, Geochim. Cosmochim. Acta, 67(1), 133-142.

Tyburczy, J. A., and H. S. Waff (1983), Electrical conductivity of molten basalt and andesite to 25 kilobars pressure: Geophysical significance and implications for charge transport and melt structure, J. Geophys. Res., 88(B3), 2413-2430, doi:10.1029/JB088iB03p02413.

Tyburczy, J. A., and H. S. Waff (1985), High pressure electrical conductivity in naturally occurring silicate liquids, in Point Defects in Minerals, Geophys. Monogr. Ser., vol. 31, edited by R. N. Shock, pp. 78-87, AGU, Washington, D.C.

Waff, H. S., and D. F. Weill (1975), Electrical conductivity of magmatic liquids: effects of temperature, oxygen fugacity and composition, Earth Planet. Sci. Lett., 28, 254-260.

Wendlandt, R. F. (1991), Oxygen diffusion in basalt and andesite melts: experimental results and discussion of chemical versus tracer diffusion, Contrib. Mineral. Petrol., 108, 463471.

\section{Appendix 1: On the difference between oxygen self-diffusion $\left(D^{*}\right)$ and chemical diffusion (D) coefficients}

As underlined by Cooper et al. (1996a), two kinds of experiments are commonly used to study diffusion-limited oxidation/reduction kinetics: oxygen self-diffusion and chemical diffusion (redox) experiments. By "chemical diffusion experiments", we consider experiments that let the sample equilibrate with a change in the gaseous atmosphere. The diffusing species, depending on the authors, are oxygen or cations or both (this study). By "oxygen self-diffusion experiments", we consider experiments (mainly isotopic) that study the tracer (or network) diffusion of oxygen. As shown in the following Figure A, several orders of magnitude separate values of chemical diffusion coefficients and oxygen self-diffusion coefficients for similar silicate melts compositions $\left(\mathrm{D}>\mathrm{D}^{*}\right)$. For example, in a basaltic melt at $1300^{\circ} \mathrm{C}$, in air, the self-diffusion coefficient of oxygen is estimated at $\sim 6.5 .10^{-12} \mathrm{~m}^{2} / \mathrm{s}$ (Canil and Muehlenbachs, 1990) while we calculated from our study a bulk chemical diffusion coefficient of $\sim 3.5 .10^{-9} \mathrm{~m}^{2} / \mathrm{s}$.

Differences have been interpreted in terms of diffusion mechanisms, chemical diffusion involving the diffusion of molecular oxygen, vacancies or cations and tracer diffusion involving the migration of ionic species (Schreiber et al., 1986; Wendlandt, 1991; Cooper et al., 1996a). 


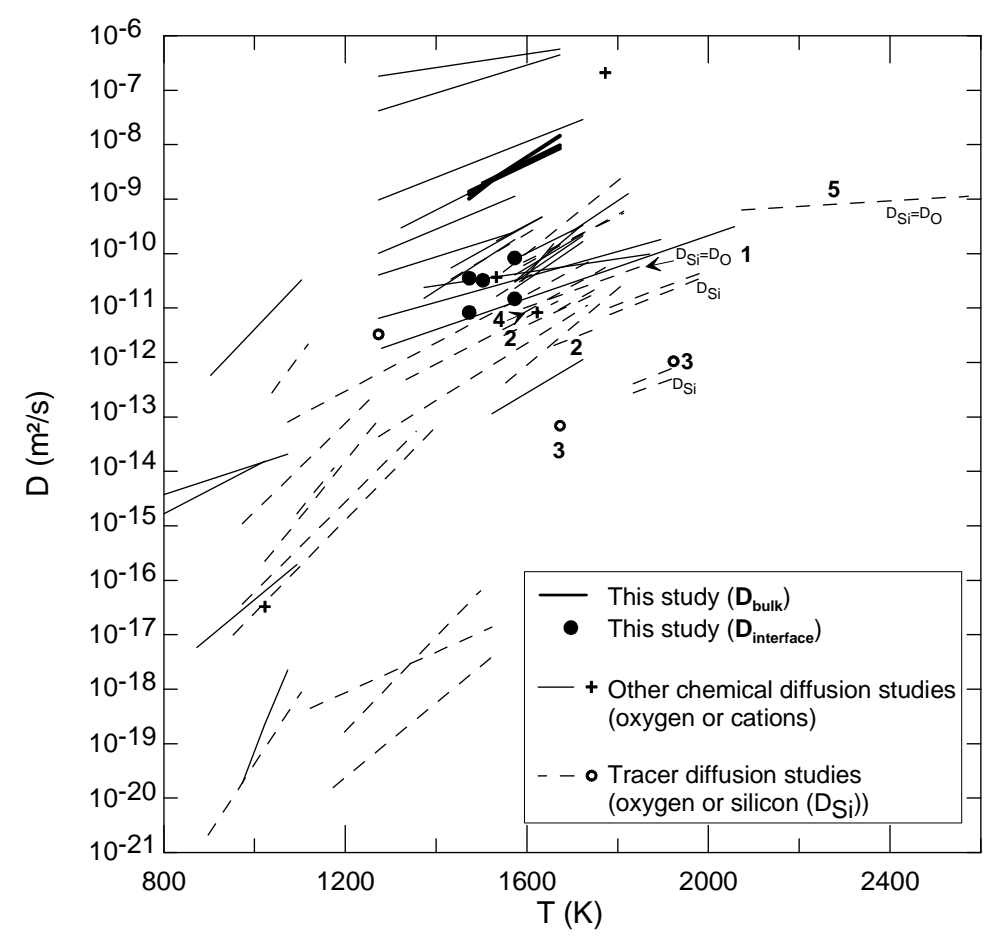

Figure A: Comparison between chemical diffusion experiments and oxygen self-diffusion experiments. Diffusion coefficients as a function of temperature. Data from this study (bold full lines and filled circles) and other chemical diffusion studies (full lines and crosses) and tracer diffusion studies (dashed lines and empty circles). Data are taken from this study and from May et al. (1974) and references therein; Schreiber et al. (1986) and references therein; Canil and Muehlenbachs (1990); Cook et al. (1990); Wendlandt (1991); Cooper et al. (1996); Cook and Cooper (2000); Smith and Cooper (2000); Reid et al. (2001); Everman and Cooper (2003); Magnien et al. (2008). 1: Tinker et al. (2003) and Lesher et al. (1996); 2: Dunn (1982); 3:

Shimizu and Kushiro (1984); 4: Canil and Muehlenbachs (1990); 5: Reid et al. (2001).

\section{Appendix 2: Estimation of a normalized driving force}

Another way to interpret the temperature-dependence of diffusivity values is to consider a normalized driving force $\Delta \mathrm{G} / \mathrm{RT}$. Over the investigated $\mathrm{T}$ range, this normalized driving force ranges from 21 at $1473 \mathrm{~K}$ to 16 at $1673 \mathrm{~K}$ (223/10.6 and $223 / 13.9$, respectively). Using the following equation (Schmalzried, 1984),

$$
k^{\prime}=\lambda . D^{\prime} \cdot(\Delta G / R T)
$$

an average diffusion coefficient D' can be deduced; k' is the reaction-rate constant (i.e. the one resulting from our electrical meaurements) and $\lambda$ is a stoechiometric factor. In Evermann and Cooper, 2003, $\lambda$ is taken as 5 . If we consider that $\lambda$ is related to the motion of oxygen, $\lambda=2$ (cf Appendix 3).

For instance, at $1473 \mathrm{~K}, \mathrm{k}^{\prime} \sim 10^{-9} \mathrm{~m}^{2} / \mathrm{s}$. Depending on the value of $\lambda, \mathrm{D}^{\prime}=2.3 .10^{-11}$ or $1.10^{-11} \mathrm{~m}^{2} / \mathrm{s}$. These D' values are consistent with self-diffusivity values for divalent cations but also for oxygen in basaltic melts (cf Fig. 10.18 in Mysen and Richet, 2005). These calculations underline that fluxes of divalent cations and oxygen probably also contribute to the redox dynamics, cooperating with alkali fluxes.

\section{Appendix 3: Relation of the mobile species fluxes to the evolution of the inner redox front}


Redox processes in magmas can be expressed by changes of the ferric/ferrous ratio (Kress and Carmichael, 1988; Dunn and Scarfe, 1986). The corresponding equilibrium can be written as follows:

$$
\mathrm{Fe}^{2+}+1 / 4 \mathrm{O}_{2}=\mathrm{Fe}^{3+}+1 / 2 \mathrm{O}^{2-}
$$

The quantity of oxygen consumed or produced in (A1) has direct implications on the structure of the melt and other cations configuration. These cations are considered to be present in the melt under molecular and ionic forms, what can be written by the following equilibria:

$$
\begin{aligned}
& \mathrm{MO}=\mathrm{M}^{2+}+1 / 2 \mathrm{O}_{2}+2 \mathrm{e}^{-}, \text {with } \mathrm{M}=\mathrm{Ca}, \mathrm{Mg} \\
& \mathrm{A}_{2} \mathrm{O}=2 \mathrm{~A}^{+}+1 / 2 \mathrm{O}_{2}+2 \mathrm{e}^{-}, \text {with } \mathrm{A}=\mathrm{Na}, \mathrm{K}
\end{aligned}
$$

Or, rescaling to the stoechiometric coefficient of oxygen in (A1):

$$
\begin{aligned}
& 1 / 2 \mathrm{MO}=1 / 2 \mathrm{M}^{2+}+1 / 4 \mathrm{O}_{2}+\mathrm{e}^{-}, \text {with } \mathrm{M}=\mathrm{Ca}, \mathrm{Mg} \\
& 1 / 2 \mathrm{~A}_{2} \mathrm{O}=\mathrm{A}^{+}+1 / 4 \mathrm{O}_{2}+\mathrm{e}^{-}, \text {with } \mathrm{A}=\mathrm{Na}, \mathrm{K}
\end{aligned}
$$

We can define the amount of cation in the oxidized form (molecular form) that is produced when one mole of $\mathrm{O}_{2}$ reacts with cation $\mathrm{i}$ (ionic form) by the following stoechiometric coefficients $\lambda$ :

$$
\lambda_{\mathrm{M} 2+}=\lambda_{\mathrm{A}+}=2
$$

Regarding oxygen anion, the reaction to consider is:

$$
1 / 2 \mathrm{O}^{2-}=1 / 4 \mathrm{O}_{2}+\mathrm{e}^{-}
$$

what leads to $\lambda_{\mathrm{O} 2}=2$.

Finally, the stoechiometric coefficient corresponding to the electron holes contribution in the redox process can be evaluated using the following equilibria:

$$
\mathrm{h}^{-}+1 / 2 \mathrm{O}^{2-}=1 / 4 \mathrm{O}_{2}+\mathrm{e}^{-}
$$

(A5) implies $\lambda_{\mathrm{h}}=4$.

The evolution of the inner redox front with time can thus be written as:

$$
\begin{aligned}
\frac{d \xi}{d t} & =\left(\sum_{M^{2+}} \lambda_{M^{2+}} \cdot j_{M^{2+}}+\sum_{A^{+}} \lambda_{A^{+}} \cdot j_{A^{+}}-j_{O^{2-}}+j_{h}\right) \cdot V m \\
& =\left(\sum_{M^{2+}} 2 \cdot j_{M^{2+}}+\sum_{A^{+}} 2 \cdot j_{A^{+}}+2 j_{O^{2-}}+4 j_{h^{\prime}}\right) \cdot V m
\end{aligned}
$$


Table 1: Composition of the starting glasses (in wt \%). Figures into brackets correspond to the concentrations of major oxides in mol \%.

\begin{tabular}{|c|c|c|c|c|}
\hline Sample & \multicolumn{2}{|c|}{ VES9 } & \multicolumn{2}{|c|}{ Kilauea } \\
\hline $\mathrm{SiO}_{2}$ & 49.2 & (54.6) & 50.0 & (55.2) \\
\hline $\mathrm{TiO}_{2}$ & 0.96 & $(0.80)$ & 2.41 & $(2.00)$ \\
\hline $\mathrm{Al}_{2} \mathrm{O}_{3}$ & 15.1 & $(9.90)$ & 13.2 & $(8.62)$ \\
\hline $\mathrm{FeO}$ & 1.73 & (1.61) & 3.16 & (2.92) \\
\hline $\mathrm{Fe}_{2} \mathrm{O}_{3}$ & 6.08 & $(2.54)$ & 8.58 & $(3.57)$ \\
\hline $\mathrm{MnO}$ & 0.20 & $(0.19)$ & 0.13 & $(0.12)$ \\
\hline $\mathrm{MgO}$ & 6.26 & (10.3) & 7.50 & (12.3) \\
\hline $\mathrm{CaO}$ & 11.5 & (13.6) & 10.6 & (12.5) \\
\hline $\mathrm{Na}_{2} \mathrm{O}$ & 1.97 & $(2.12)$ & 2.29 & $(2.45)$ \\
\hline $\mathrm{K}_{2} \mathrm{O}$ & 5.98 & $(4.23)$ & 0.38 & $(0.27)$ \\
\hline $\mathrm{F}$ & 0.14 & & - & \\
\hline $\mathrm{Cl}$ & 0.12 & & - & \\
\hline S & 0.05 & & - & \\
\hline Total & 99.7 & (100) & 97.89 & (100) \\
\hline $\mathrm{NBO} / \mathrm{T}$ & 0.73 & & 0.80 & \\
\hline
\end{tabular}




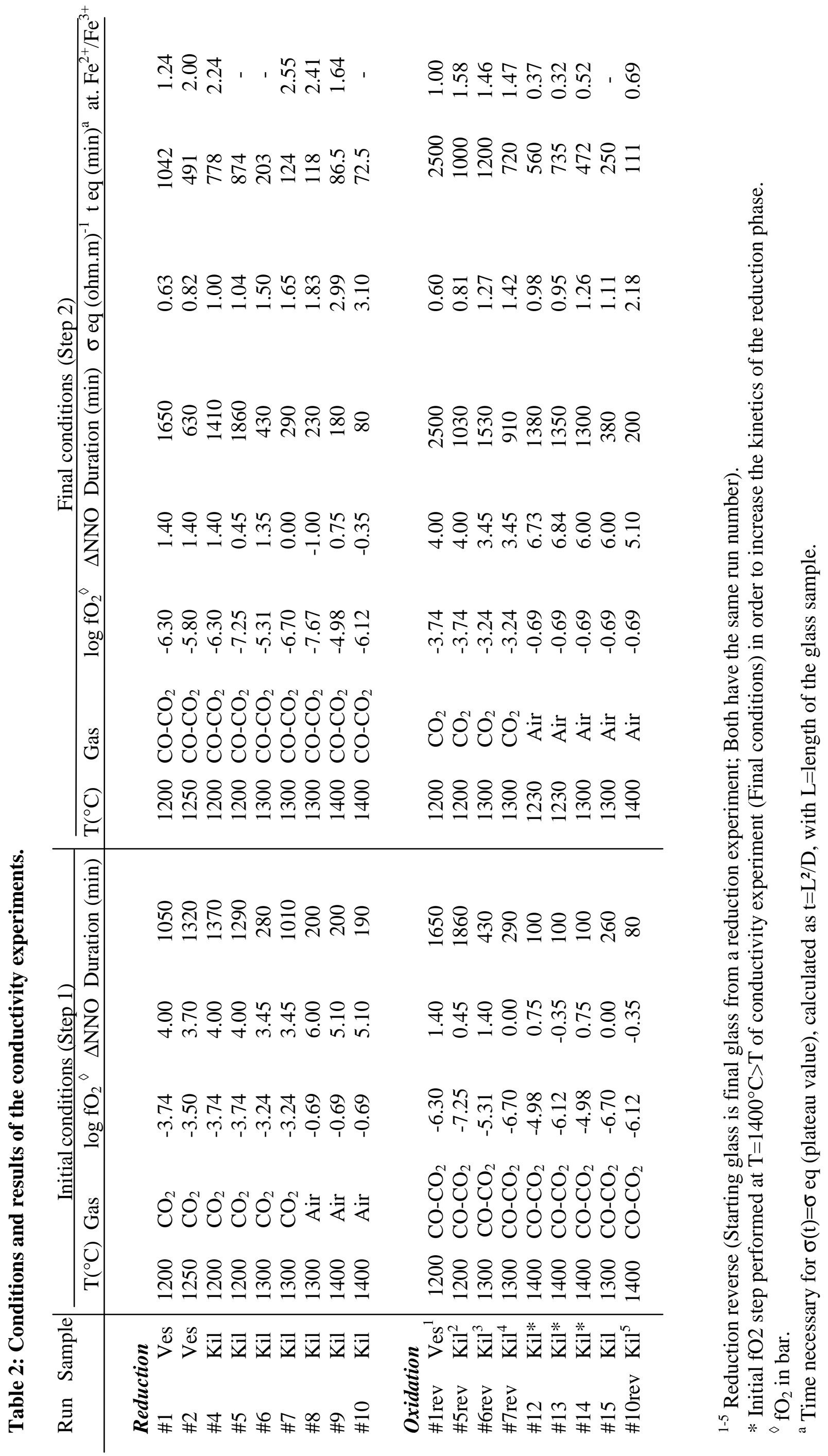


Table 3: Conditions and results of the analytical experiments.

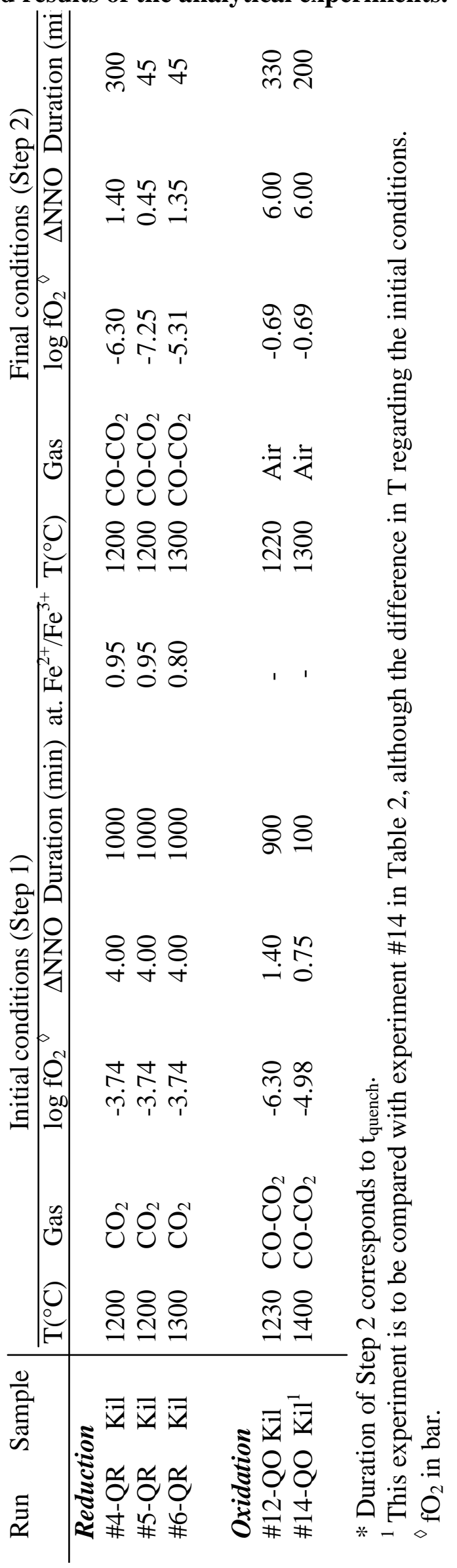


Table 4: Arrhenius parameters for the investigated samples.

Gas

$\log \mathrm{fO}_{2}{ }^{\diamond} \quad \Delta \mathrm{NNO} \quad \mathrm{Fe}^{2+} / \mathrm{Fe}^{3+}(\%$ at $) \quad$ Lno $\sigma_{0}(\text { ohm.m })^{-1} \mathrm{Ea}_{\sigma}$

$(\mathrm{kJ} / \mathrm{mol})$

Mt. Vesuvius sample (T range [1200-1250 $\left.{ }^{\circ} \mathrm{C}\right]$ )

$\mathrm{CO}-\mathrm{CO}_{2}$ mixture $1 \quad[-6.30 ;-5.80]$

$[1.24 ; 2.00]$

7.57

98

Kilauea sample $\left(\mathrm{T}\right.$ range $\left.\left[1200-1400^{\circ} \mathrm{C}\right]\right)$

Air

0.68

$\sim 7$

$[0.32 ; 0.92]$

7.21

90

$\mathrm{CO}_{2}$

$[-3.74 ;-3.24] \quad[3.45 ; 4.00] \quad[1.22 ; 1.58]$

9.16

114

$\mathrm{CO}-\mathrm{CO}_{2}$ mixture 1

$[-6.30 ;-4.98] \quad[0.75 ; 1.40] \quad[1.64 ; 2.24]$

9.20

113

$\mathrm{CO}-\mathrm{CO}_{2}$ mixture 2

$[-7.25 ;-6.12] \quad[-0.35 ; 0.45]$

$2.55^{*}$

9.16

112

${ }^{\ominus} \mathrm{fO}_{2}$ in bar.

*one wet chemical analysis (run \#7 in Table 2). 


\section{Figure captions}

Figure 1: Description of (A) the conductivity cell and (B) the sample configuration for analytical experiments. The arrows represent the exchange with the gaseous atmosphere at the unique interface sample/gas. The straight lines represent the three types of microprobe traverses performed after the redox experiments (see text).

Figure 2: Electrical response observed in the Nyquist plan (Z', Z'') for the Kilauea basalt at $1300^{\circ} \mathrm{C}$, during oxidation in air. The first part of the response $\left(Z^{\prime}<R\right)$ represents the electrical response of the sample while the second part $\left(Z^{\prime}>R\right)$, represents the effect of the interface between the sample and the electrode. R (resistance of the sample (ohm)) is obtained for Z" = 0 and represents the real part of the complex impedance (here, $\mathrm{R} \sim 18.5 \mathrm{ohm}$ ).

Figure 3: Iron losses, example of the redox experiment at $1200^{\circ} \mathrm{C}$ (run \#5). A: Molar fraction of metallic iron in the Pt electrode after. The EMPA profile shows that iron contamination affects the electrode on a distance $<100$ microns. B: Concentration of total iron in mol of oxide normalized to 100 . No noticeable iron depletion is detected in the sample, even at the interface glass/Pt electrode. Error estimation is presented in the box.

Figure 4: Electrical conductivity at the chemical equilibrium of the Kilauea sample as a function of oxygen fugacity, for $\mathrm{T}$ ranging from $1200^{\circ} \mathrm{C}$ to $1400^{\circ} \mathrm{C}$. The conductivity slightly increases with decreasing the $\mathrm{fO}_{2}$. The electrical conductivity is more strongly dependent on $\mathrm{T}$ than $\mathrm{fO}_{2}$. Experimental conditions are indicated in Table 2. Dashed lines correspond to Eq.4. The electrical conductivity of the PG-16 basaltic melt at $1400^{\circ} \mathrm{C}$ from Waff and Weill (1975) (WW75) is shown for comparison.

Figure 5: Conductivity transients in oxidation and reduction reactions. A: Reduction example (run \#6); B: Oxidation example (run \#15). The solid lines correspond to the calculated conductivity with the diffusion equation of Crank (see text). C: Advancement of oxidation reaction in air and $\mathrm{CO}_{2}$ as a function of time. The diffusion profile obtained in air contrasts with the more linear trend obtained under $\mathrm{CO}_{2}$. Triangles and diamonds underline that the non diffusion kinetics under $\mathrm{CO}_{2}$ is not function of the gas flow in the furnace. Straight line is just a guide for the eyes.

Figure 6: Microprobe traverses from the gas/sample interface in Kilauea samples quenched during redox experiments and after conductivity experiment. A) $1300^{\circ} \mathrm{C}, \log \mathrm{fO}_{2}=-5.31, \mathrm{t}$ quench $=45 \mathrm{~min}$ (run \#6-QR); B) $1200^{\circ} \mathrm{C}, \log \mathrm{fO}_{2}=-6.30$, t quench=300min (run \#4-QR); C) $1300^{\circ} \mathrm{C}, \log \mathrm{fO}_{2}=-0.68$, t quench $=300 \mathrm{~min}$ (run \#14-QO); D) $1230^{\circ} \mathrm{C}, \log \mathrm{fO}_{2}=-0.69$ (run\#12). Traverse D stresses that chemical compositions of starting glass and glass after the conductivity experiment are similar. Oxides concentrations are given in mol \%. Variations in oxides concentrations allow to distinguish an interface zone, from the interface with gas to $\xi$ ' (dashed line, approximate localisation). The second internal front, $\xi$ ', delimiting the unreacted melt, is calculated using D values from Eq.7 (see text for details).

Figure 7: A) Ferrous-ferric ratio with $\triangle \mathrm{NNO}$ for conductivity and analytical experiments performed on the Kilauea sample. See Tables 2 and 3 for experimental conditions. B) Equilibration time as a function of the ferrous-ferric ratio for the Kilauea sample. Examples of a reduction at $1200^{\circ} \mathrm{C}, \log \mathrm{fO}_{2}=-6.30$ and of an oxidation at $1300^{\circ} \mathrm{C}$, in air. The small error bars underline the high reproducibility of the wet chemical analyses. Crosses represent the 
attainment of chemical equilibrium (plateau value), determined using electrical measurements (see text for details). The curves are just a guide for the eye.

Figure 8: Comparison between the evolution of the electrical response of the sample and the evolution of the ferrous-ferric ratio (in \%). Data points fall on the straight line 1:1, indicating similar kinetics of the evolution of the conductivity and of the redox ratio in the melt.

Figure 9: Calculated bulk diffusivity values. A) Diffusion coefficients calculated using the equation of diffusion (Eq. 7, cf Crank, 1975, p.48) vs temperature. Data are presented for both reduction (open diamonds: VES sample; filled diamonds: Kil sample) and oxidation (stars, Kil sample). Experimental conditions are detailed in Table 2. The general regression (straight line) yields a correlation factor of 0.81 , underlining similar kinetics for both reduction and oxidation. The similar D values for the two basaltic samples can be explained by the small differences in the chemical compositions (Table 1). B) Compensation plot for the diffusion coefficients from this study (triangles, calculated using Eq. 7) and from other studies, attributed to either the diffusion of oxygen or of divalent cations (D: Dunn, 1983; W: Wendlandt, 1991; C et al. 96: Cooper et al., 1996; EC: Everman and Cooper, 2003; Do: Doremus, 1960; LW: Lawless and Wedding, 1970; SG: Sasabe and Goto, 1974; SH: Semkow and Haskin, 1985; S et al.: Schreiber et al., 1986; CC: Cook and Cooper, 2000; C et al. 90: Cook et al., 1990). Data for natural and synthetic silicate melts. The dashed line represents the compensation law for natural melts (Eq.9). C) Calculated diffusing rates as a function of oxygen fugacity variations (proportional to the driving potential). Data at $1200^{\circ} \mathrm{C}$ (Kilauea and Mt Vesuvius samples), $1300^{\circ} \mathrm{C}$ and $1400^{\circ} \mathrm{C}$ (Kilauea sample).

Figure 10: Redox dynamics in the Kilauea basalt in the T range $1200-1400^{\circ} \mathrm{C}$. Both reduction and oxidation involve chemical reactions at the free surface of the sample $\left(\xi_{0}\right)$ and at two internal fronts ( $\xi^{\prime}$ and $\xi$ '). At $\xi_{0}$, oxygen is released or incorporated in the melt, with h being consumed or absorbed, respectively. At the internal front ( $\left.\xi^{\prime}\right), \mathrm{Fe}^{3+}$ is reduced to $\mathrm{Fe}^{2+}$ (reduction) or $\mathrm{Fe}^{2+}$ is oxidized to $\mathrm{Fe}^{3+}$ (oxidation), implying variations on $\mathrm{Na}^{+}$mobility, and thus on the electrical response of the melt (see text for details). The measured bulk diffusion coefficient corresponds to the second internal front ( $\xi$ "). Competitive mechanisms occur between oxygen and cations diffusion. The smaller amounts of network-modifier cations compared to oxygen anions imply electron holes to charge-balance $\mathrm{O}^{2-}$ fluxes. The high diffusivities of h probably enhance oxygen and cations diffusion, since the $\mathrm{D}$ values are deduced from electrical measurements and are thus related to charged mobile species. Oxygen probably moves in the melt as both ionic $\left(\mathrm{O}^{2-}\right)$ species, as underlined by several studies (e.g. Goldman and Gupta, 1983; Dunn, 1983; Schreiber et al., 1986; Wendlandt, 1991) and as oxide species, since spectroscopic studies showed that most bridging oxygens have cations in their first coordination shell, forming Q species (e.g. Stebbins, 1995). 
Figure 1

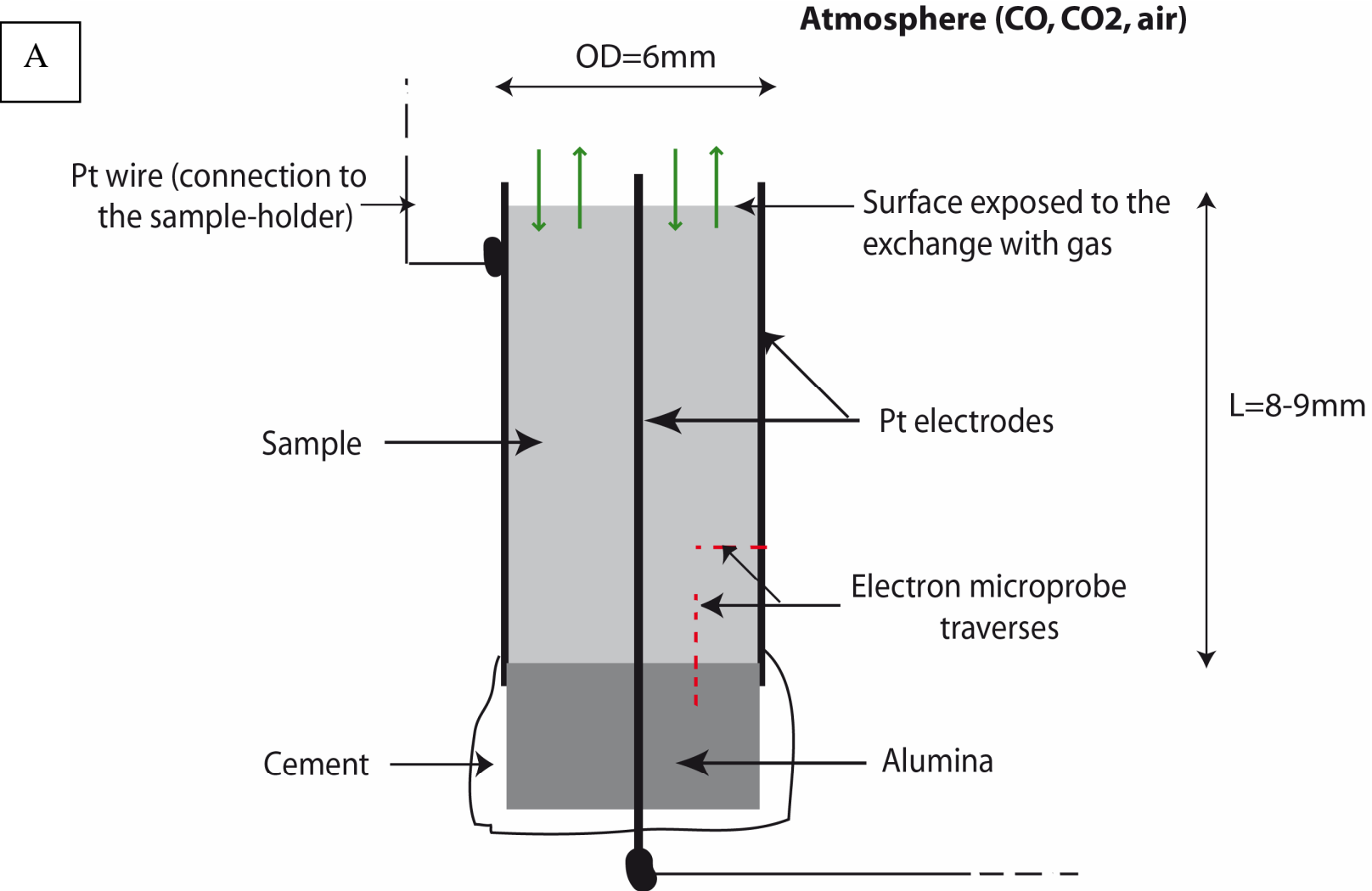

B

Atmosphere (CO, CO2, air)

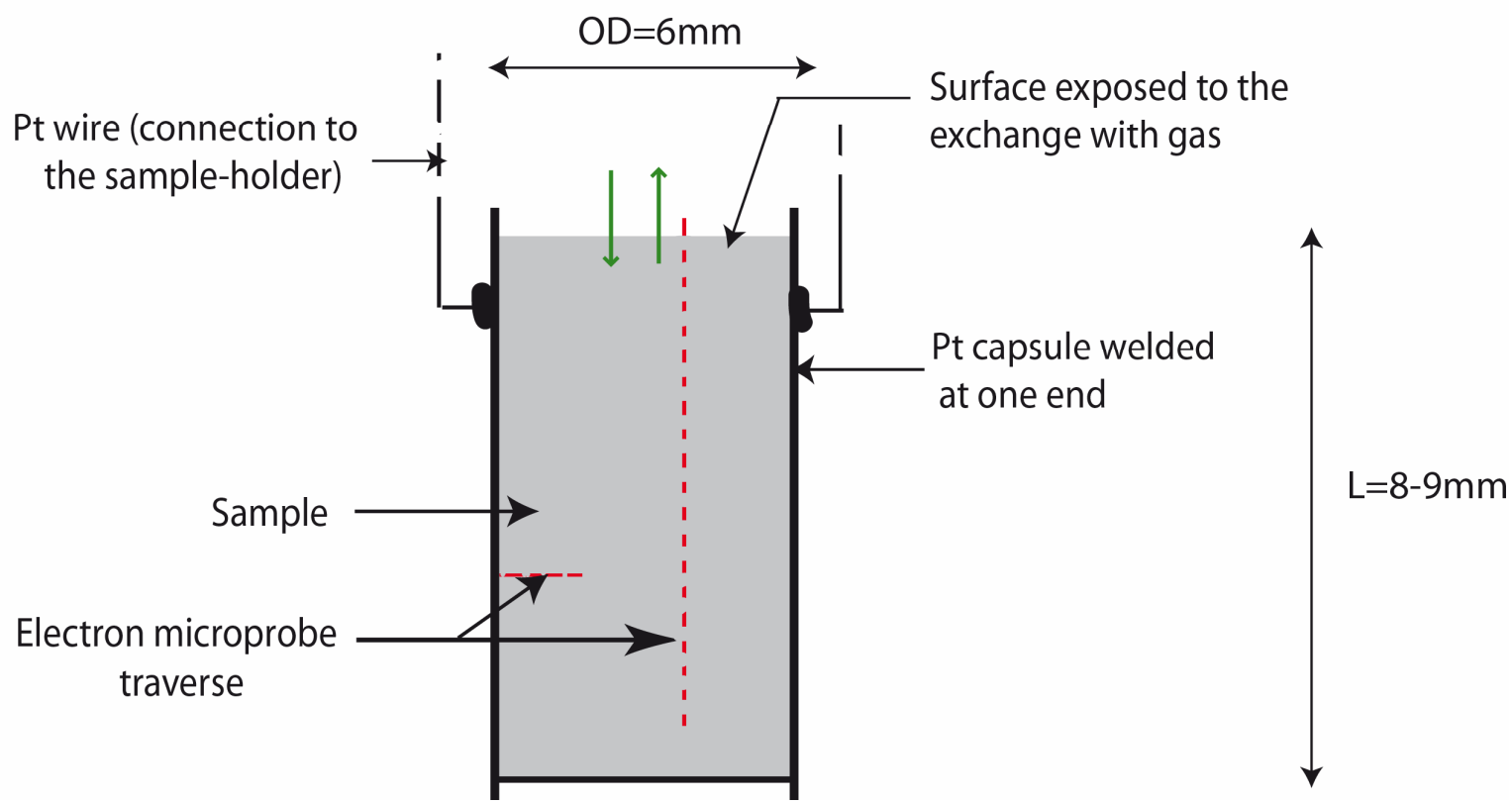


Figure 2

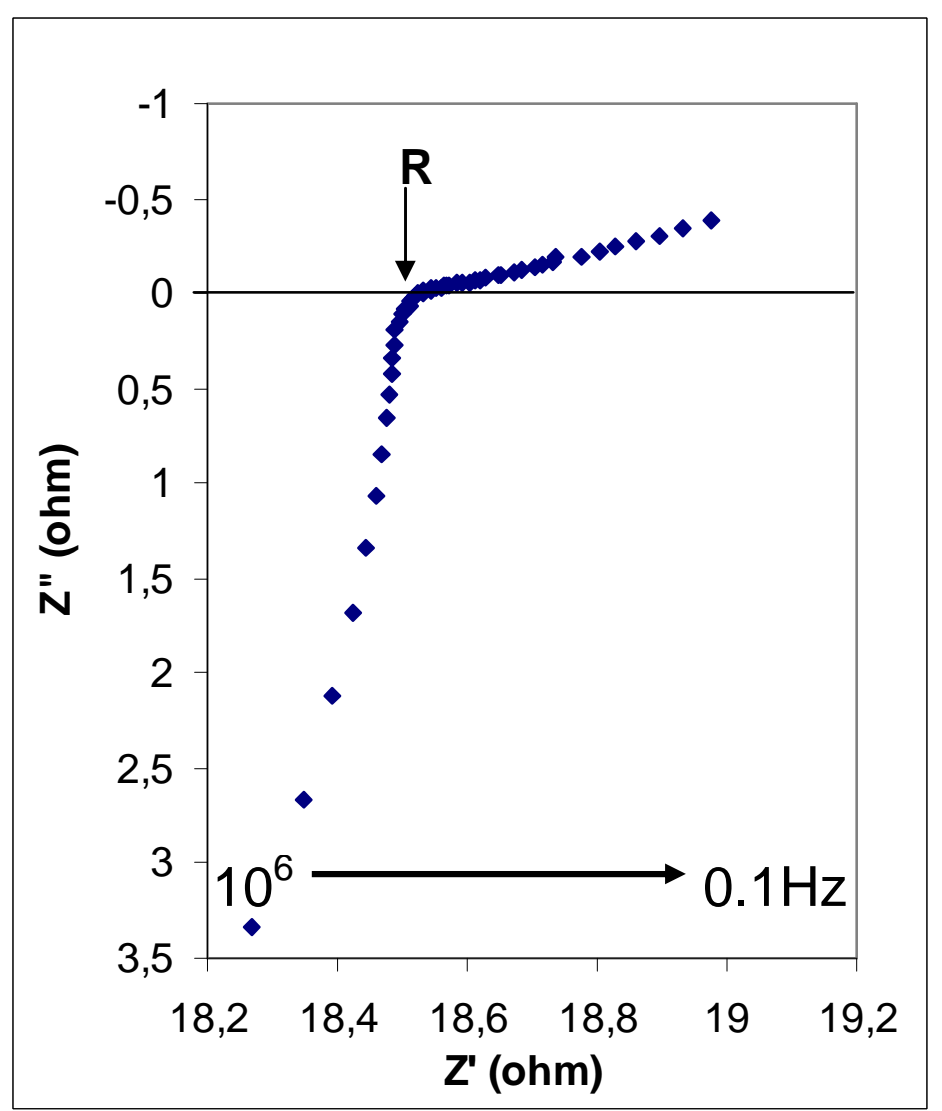


Figure 3

A)

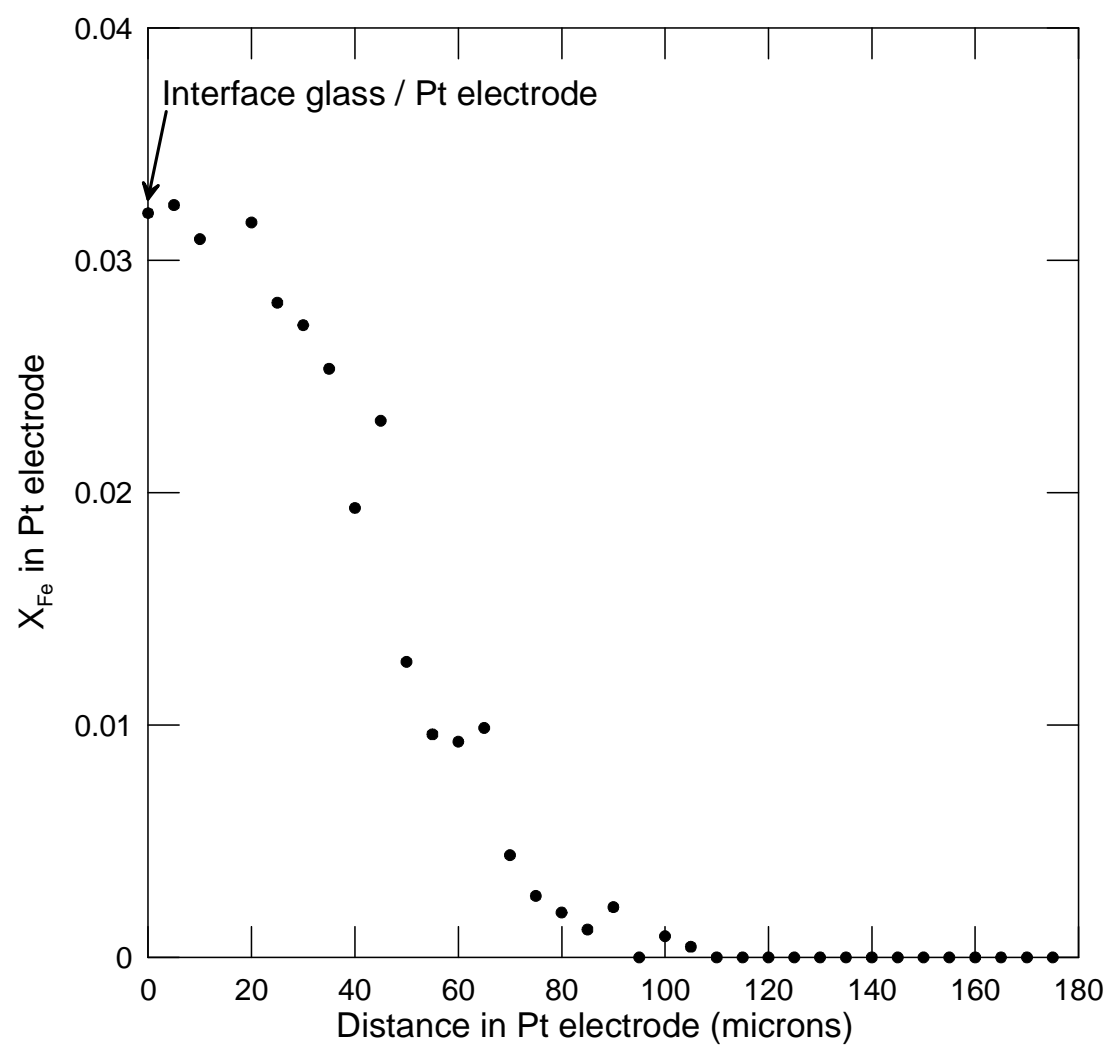

B)

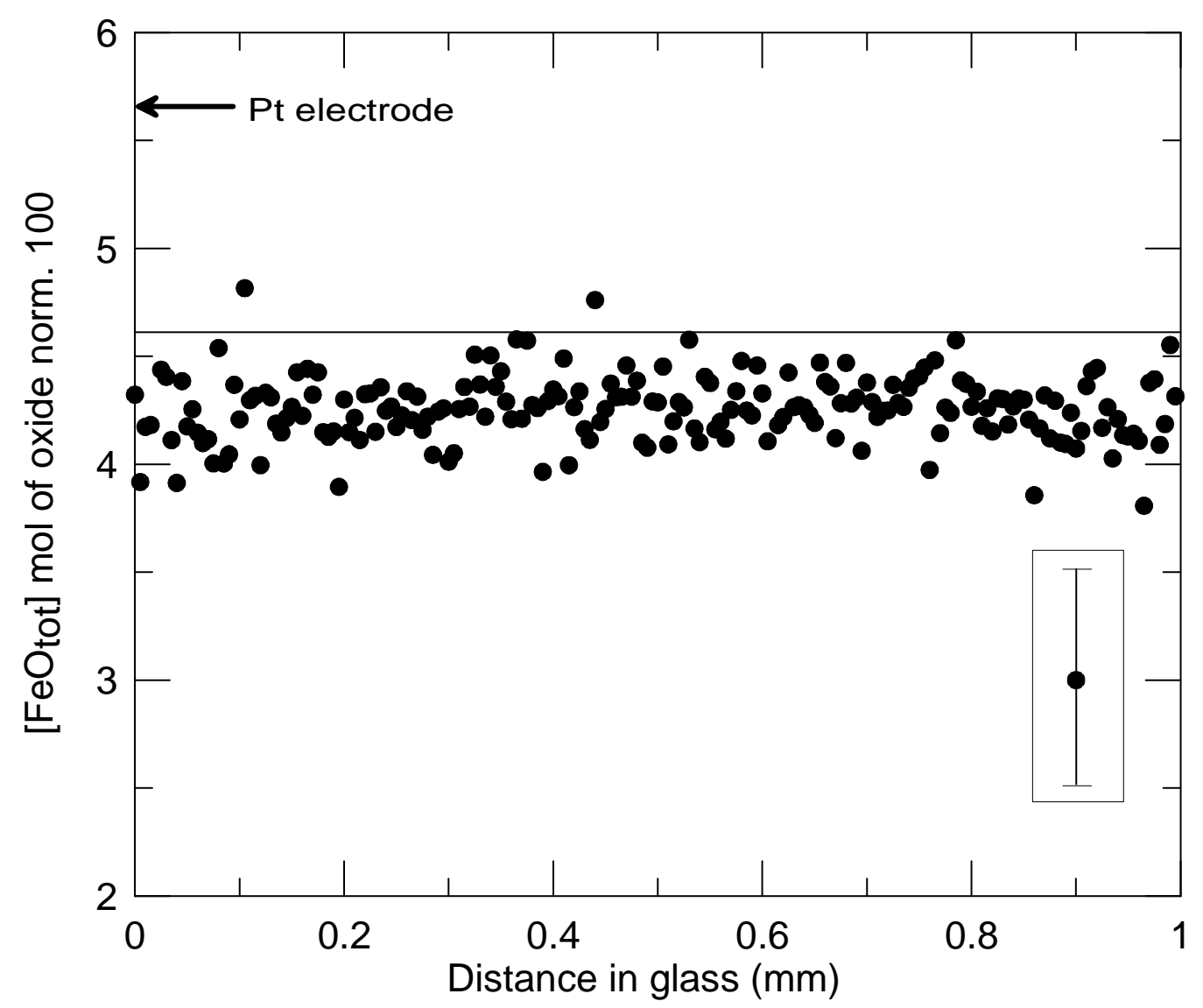


Figure 4

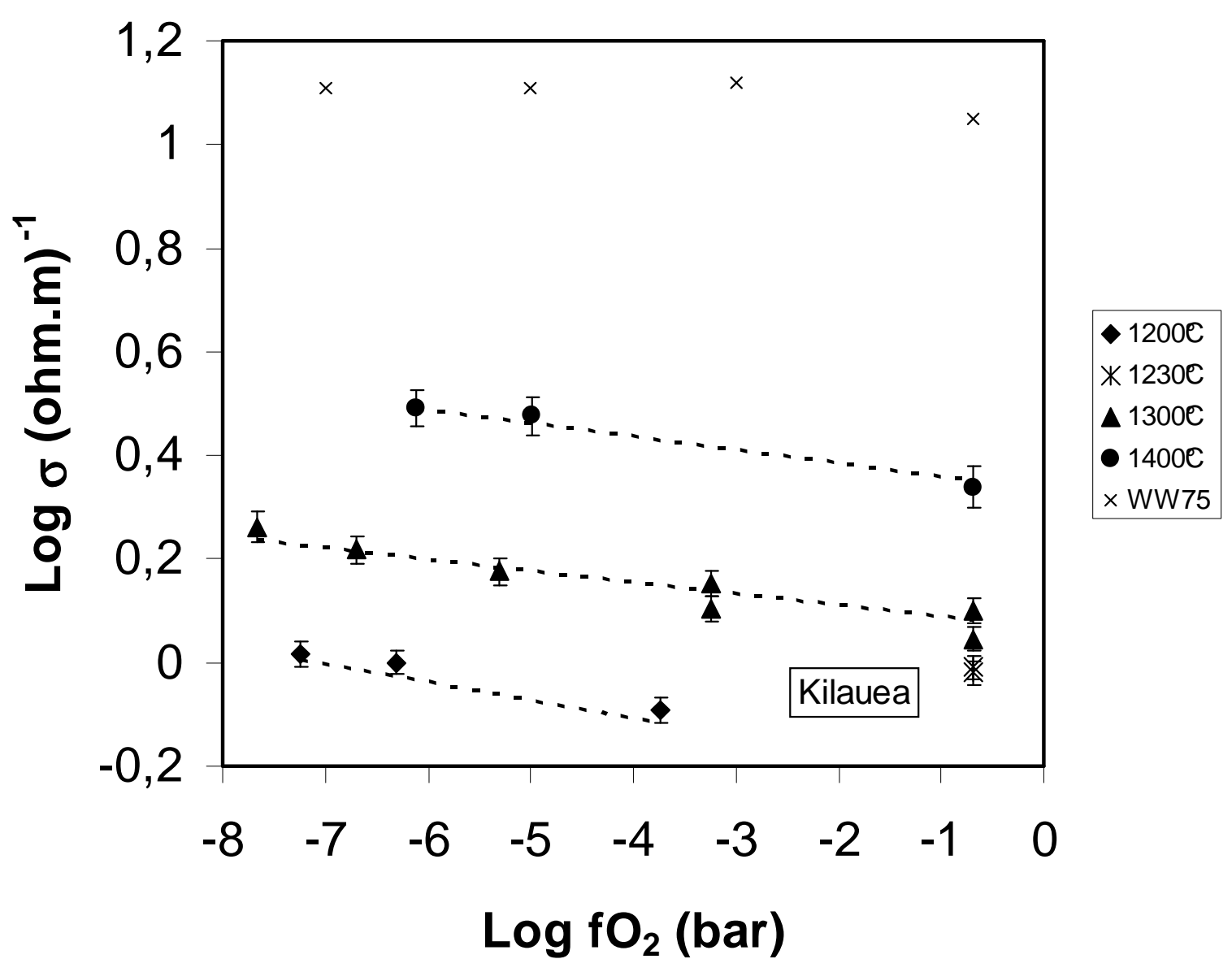


A)

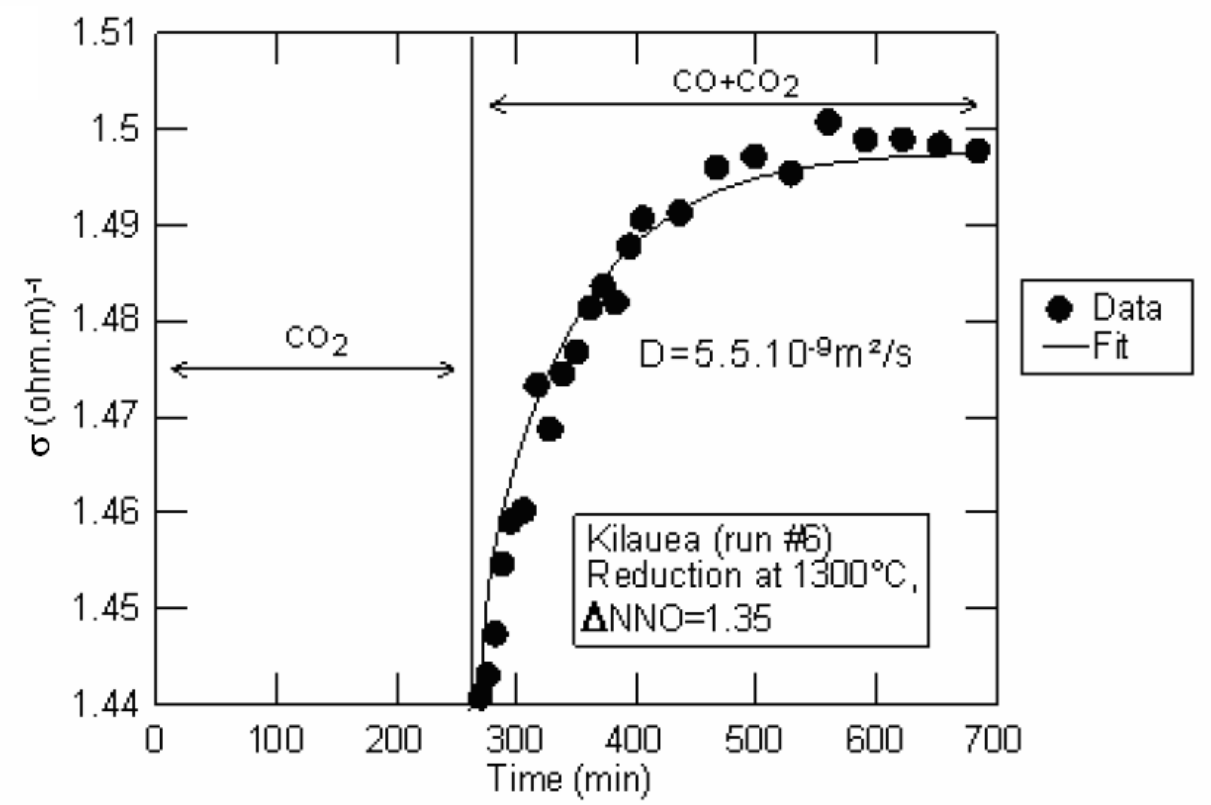

B)

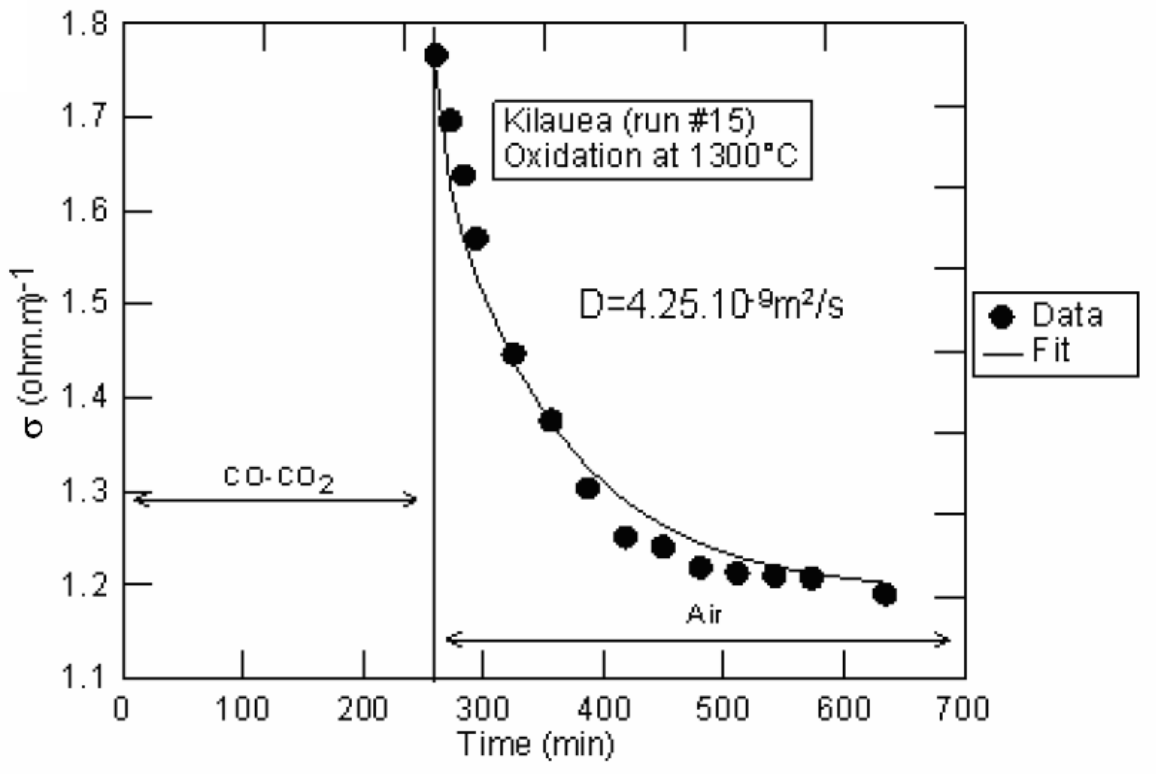

C)

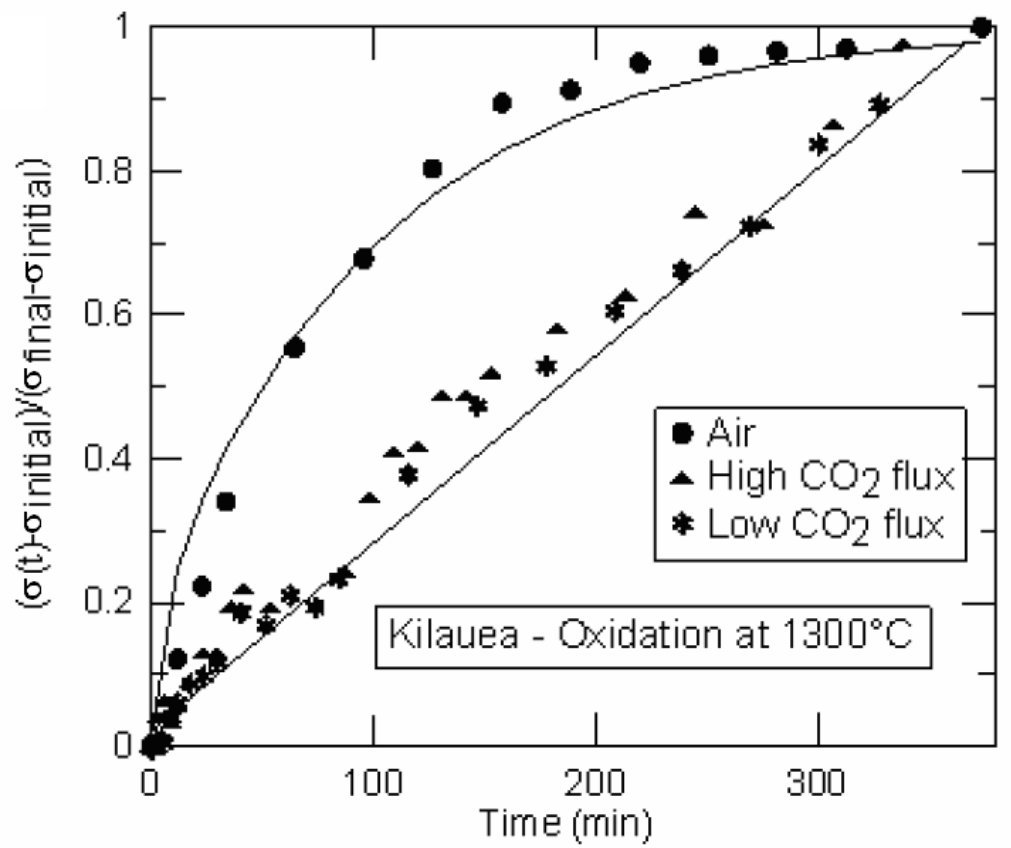


Figure 6

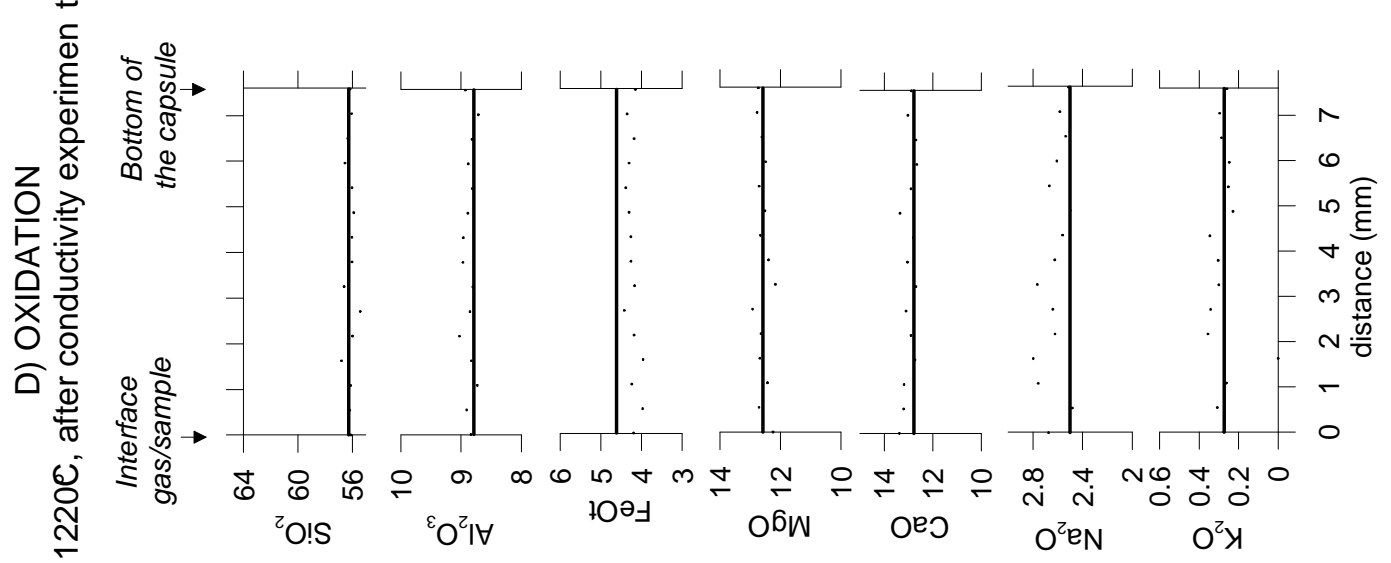

¿
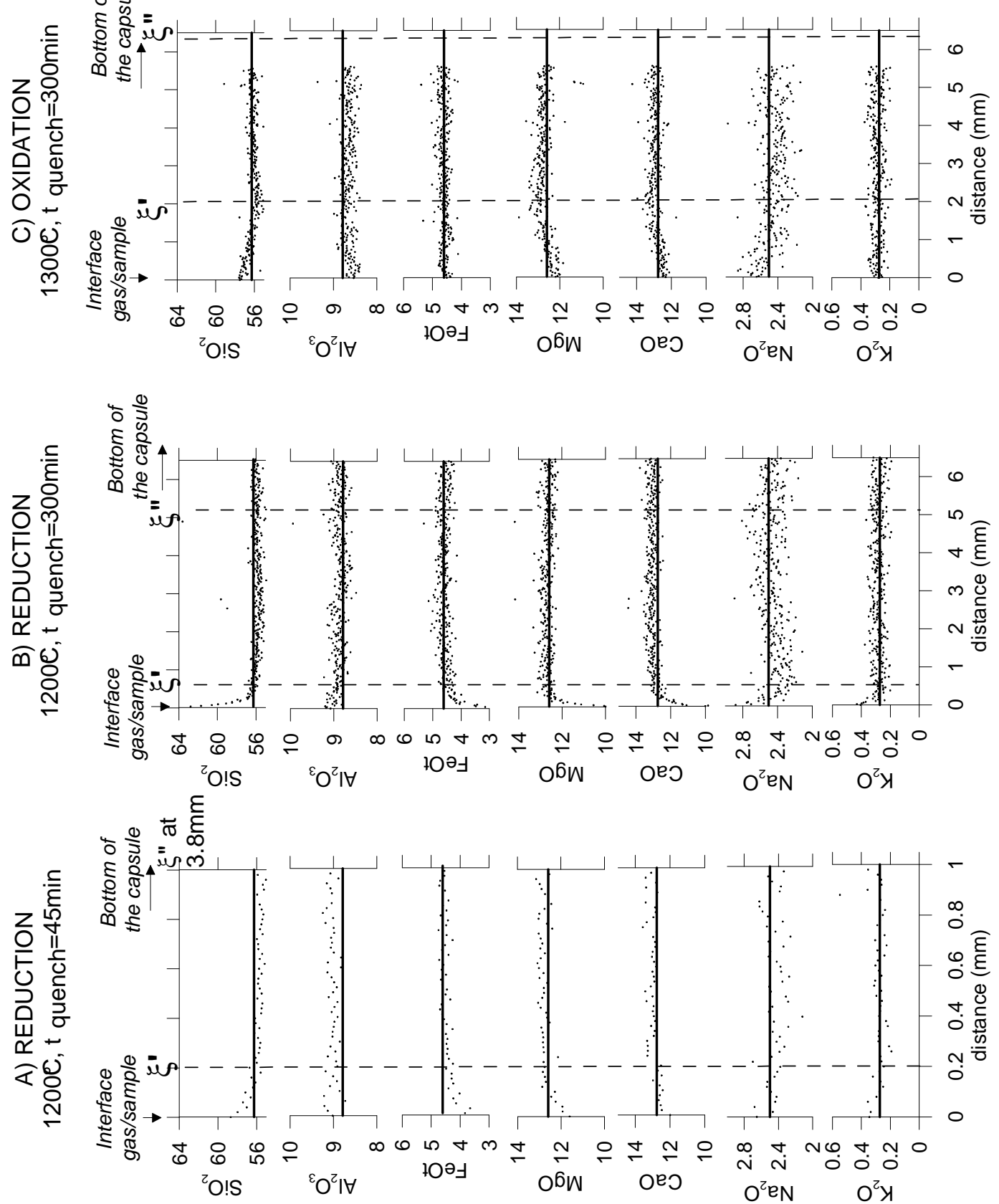
Figure 7

A)

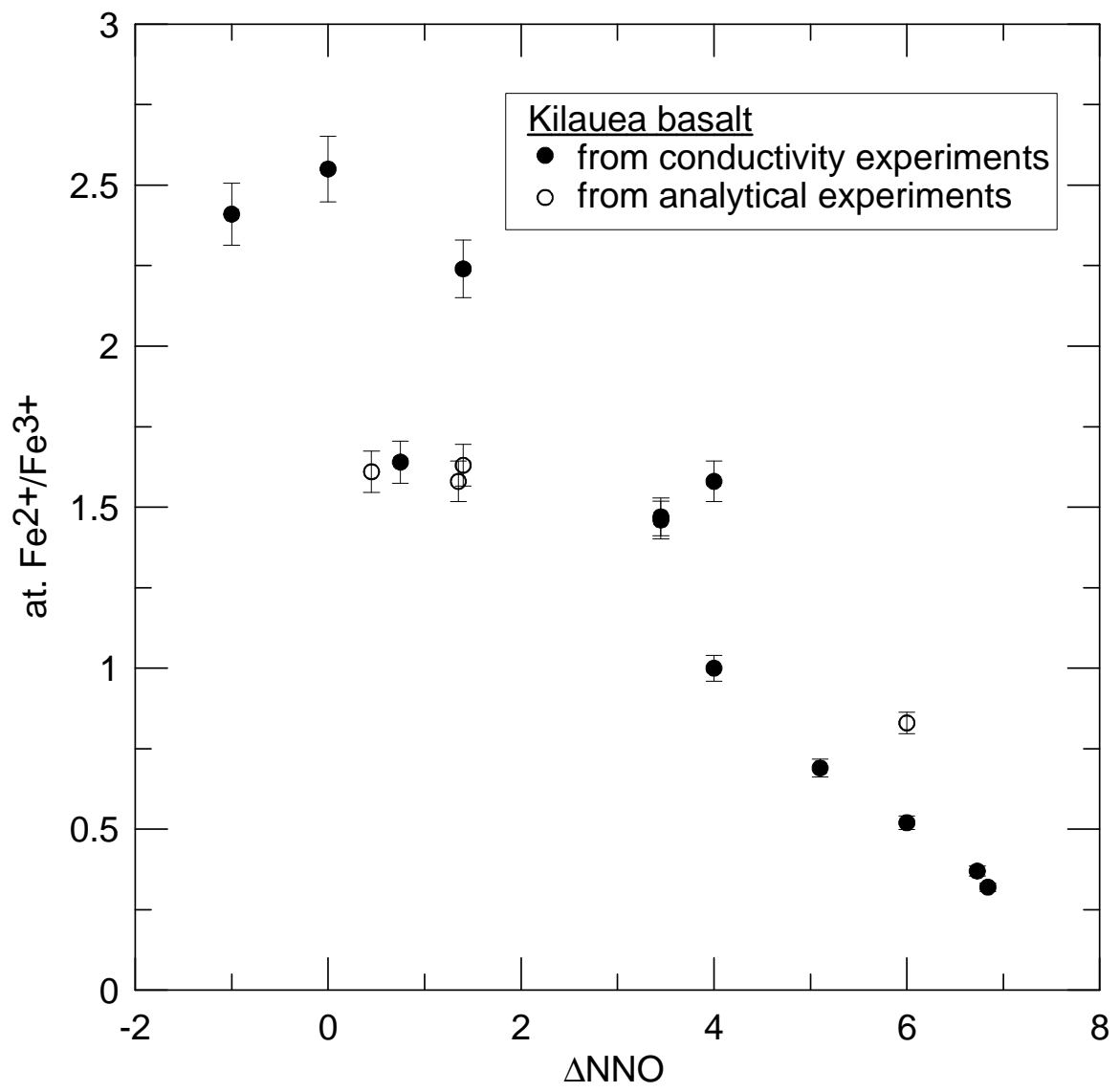

B)

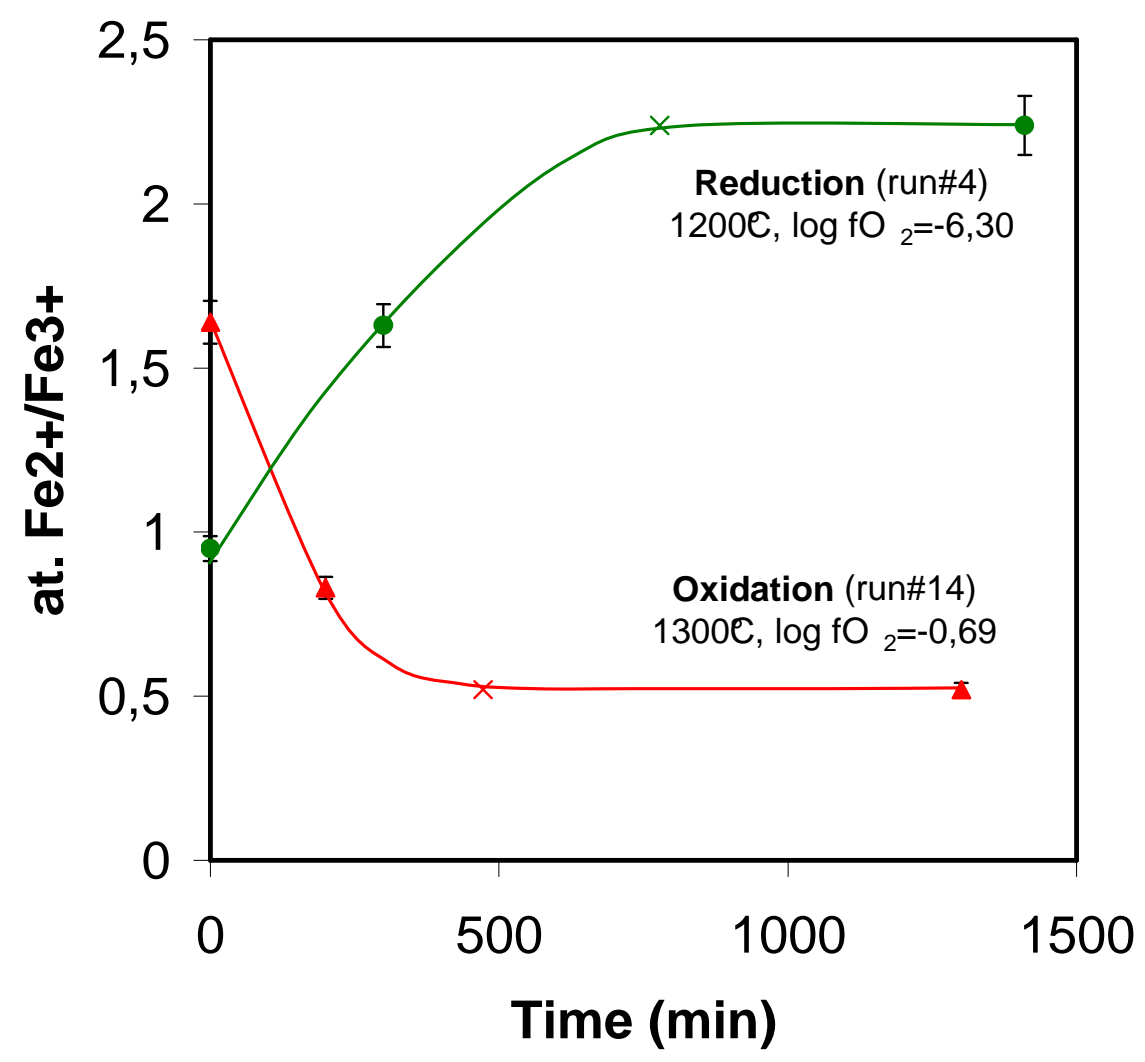


Figure 8

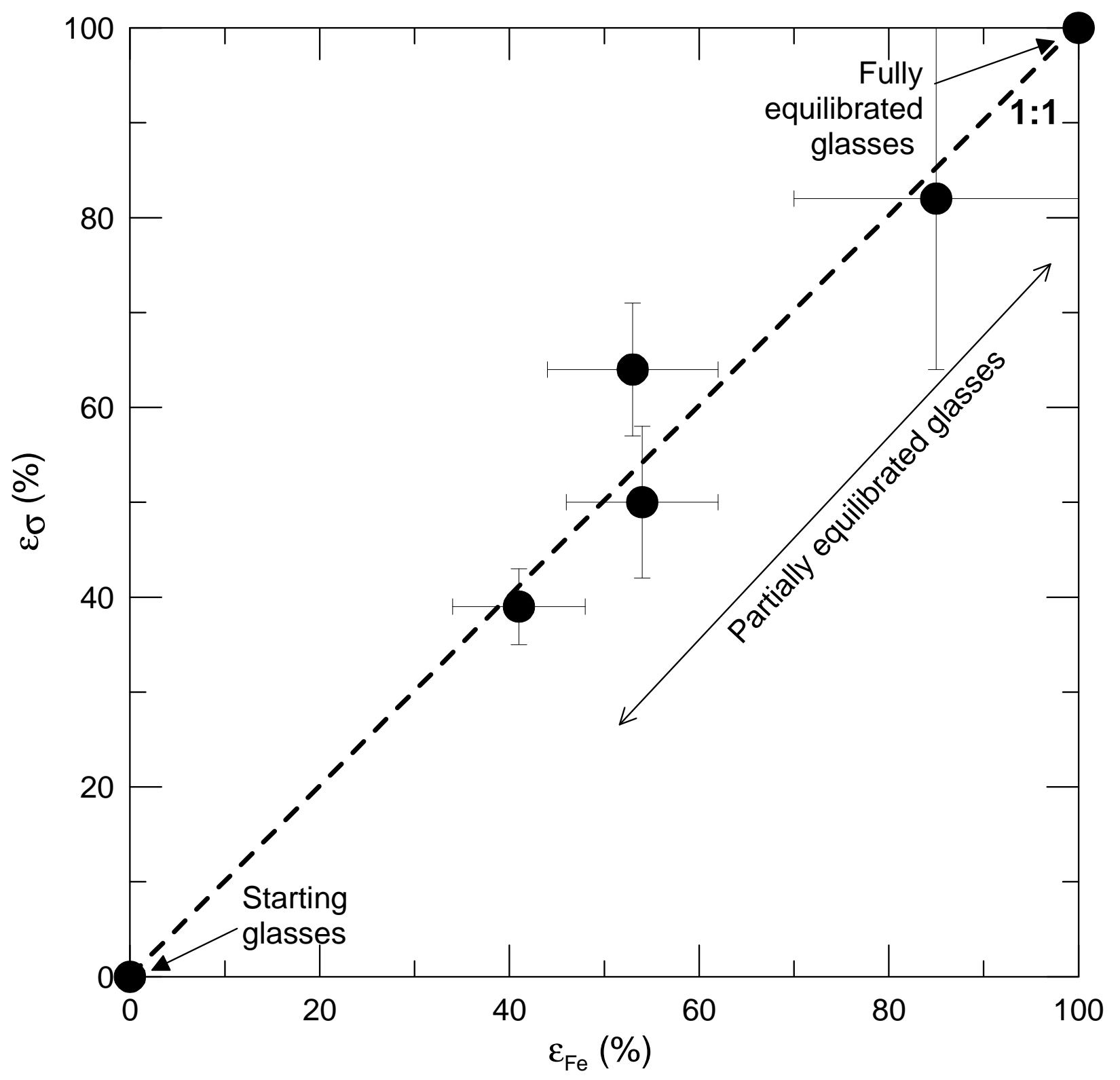


Figure 9

A

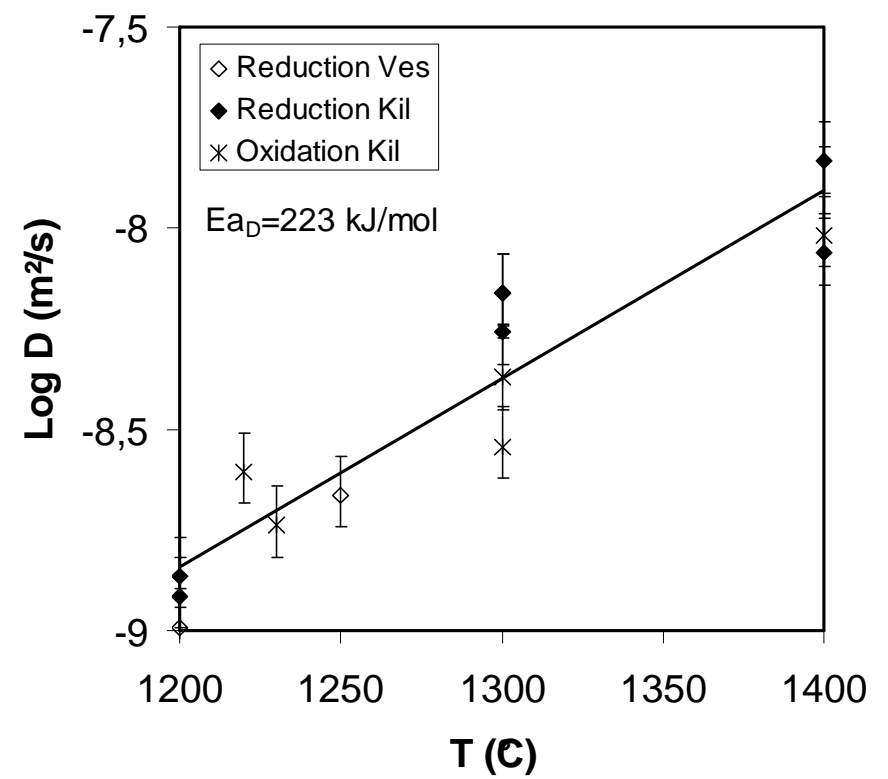

B

C
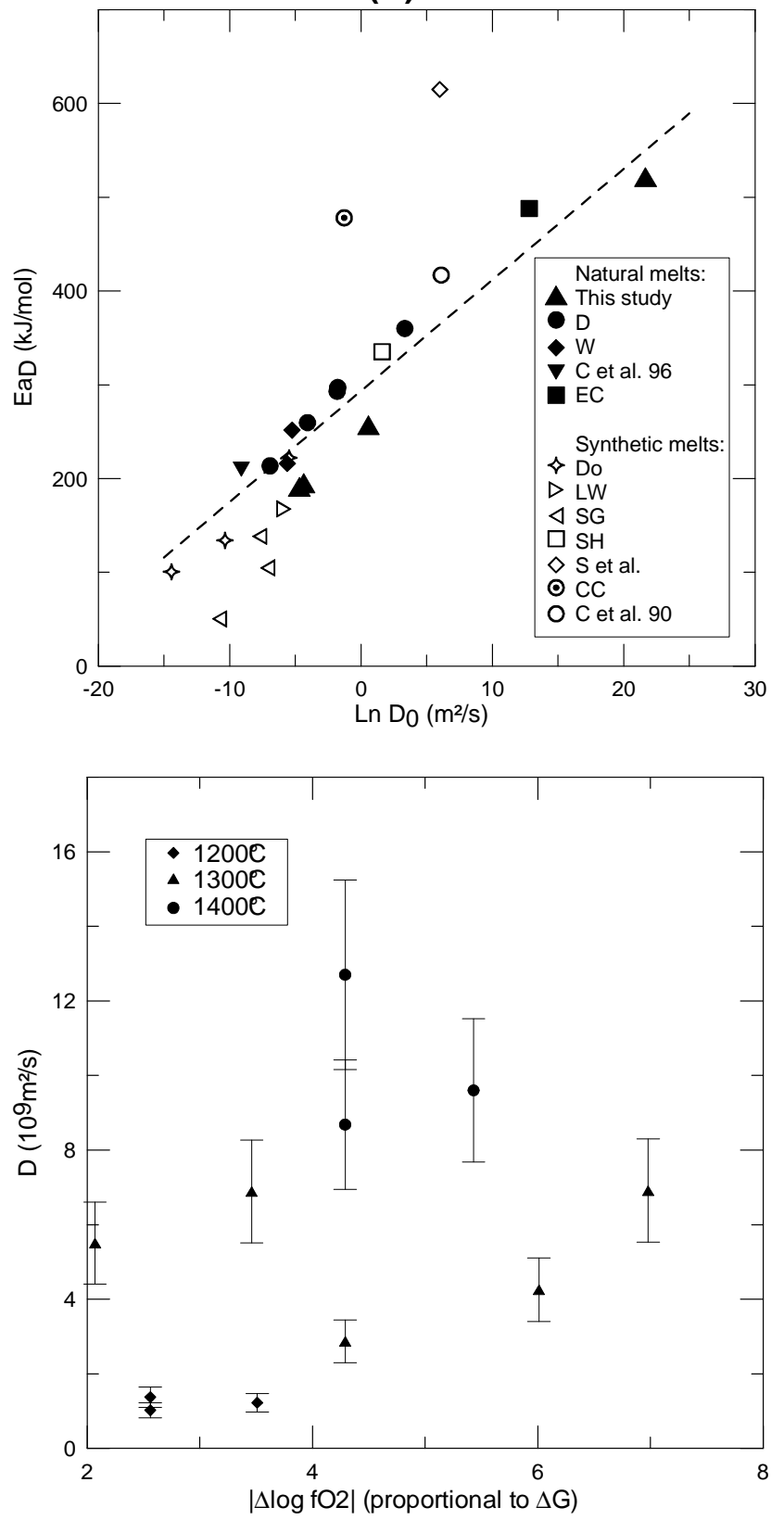

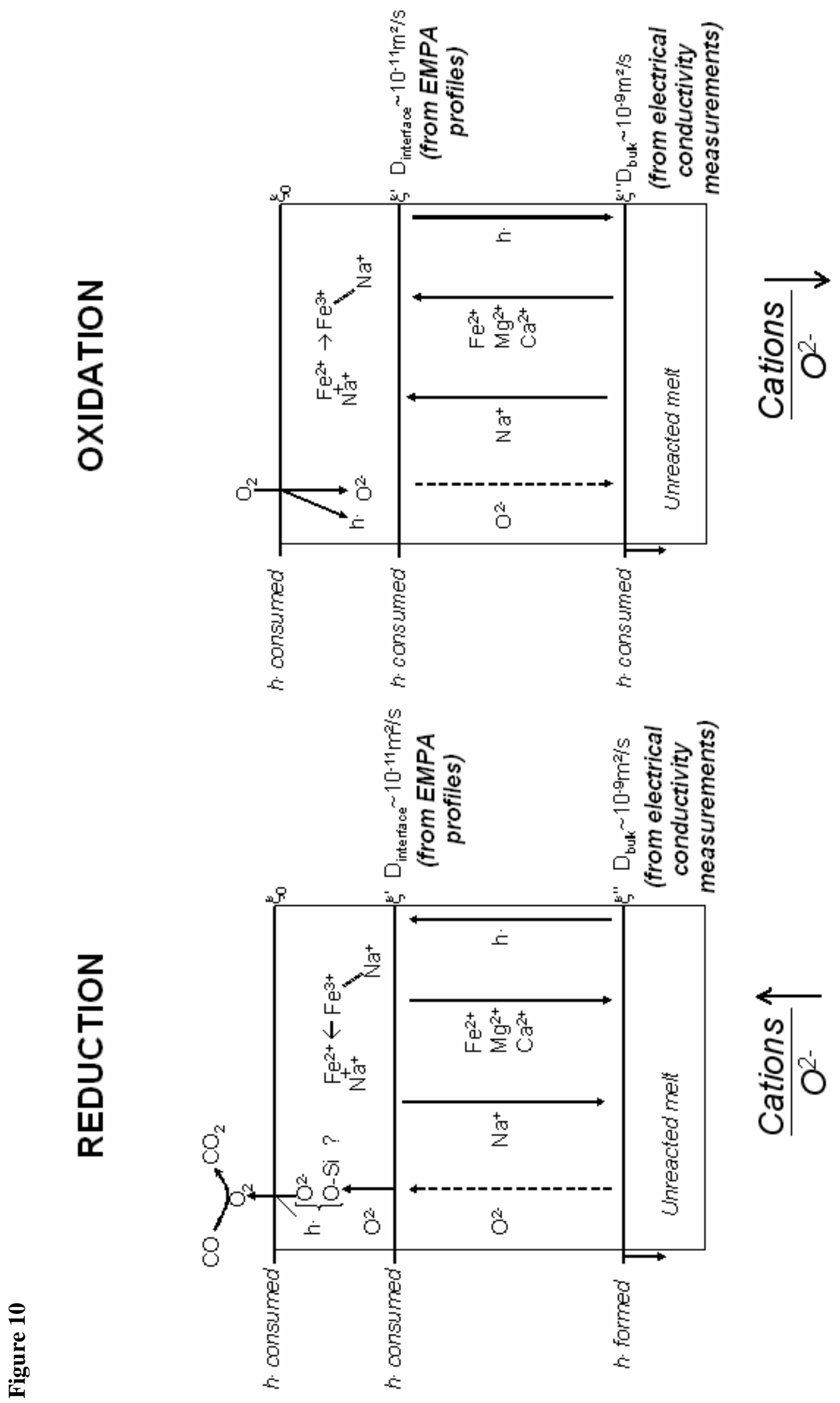